Juliana Gusson Roscito

Desenvolvimento embrionário e a evolução da fossorialidade nos lagartos da tribo Gymnophthalmini (Squamata, Gymnophthalmidae)

São Paulo 2010 
Juliana Gusson Roscito

\section{Desenvolvimento embrionário e a evolução da fossorialidade nos lagartos da tribo Gymnophthalmini (Squamata, Gymnophthalmidae)}

Embryonic development and the evolution of fossoriality in Gymnophthalmini lizards

(Squamata, Gymnophthalmidae)

Tese apresentada ao Instituto de Biociências da Universidade de São Paulo, para a obtenção de Título de Doutor em Ciências, na Área de Zoologia

Orientador: Miguel Trefaut Rodrigues

São Paulo 2010 
Roscito, Juliana

Desenvolvimento embrionário e a evolução da

fossorialidade nos lagartos da tribo Gymnophthalmini (Squamata, Gymnophthalmidae)

$279 \mathrm{pg}$.

Tese (Doutorado) - Instituto de Biociências da Universidade de São Paulo. Departamento de Zoologia.

1. Desenvolvimento

2. Evolução

3. Fossorialidade

4. Gymnophthalmidae

I. Universidade de São Paulo. Instituto de Biociências.

Departamento de Zoologia.

\section{Comissão julgadora:}

Prof(a). Dr(a).

$\operatorname{Prof}(\mathrm{a}) . \operatorname{Dr}(\mathrm{a})$
$\operatorname{Prof}(\mathrm{a}) . \operatorname{Dr}(\mathrm{a})$

$\operatorname{Prof}(\mathrm{a}) . \operatorname{Dr}(\mathrm{a})$

Prof(a). Dr(a). 


\section{RESUMO}

A história evolutiva da tribo Gymnophthalmini (família Gymnophthalmidae) é caracterizada por modificações morfológicas relacionadas à evolução de planos corpóreos serpentiformes adaptados à vida fossorial. As adaptações apresentadas por estas espécies (especialmente o alongamento do corpo e a redução dos membros) são frequentemente observadas em diversos outros grupos de Squamata.

A formação do padrão corpóreo é coordenada por uma rede de regulação complexa que atua durante o desenvolvimento embrionário e, muitas vezes, mudanças sutis nesta rede podem resultar em alterações fenotípicas drásticas, levando à mudanças evolutivas nas formas corpóreas.

Neste contexto, o grupo Squamata é um ótimo modelo de pesquisa para estudos sobre a evolução das formas, já que diversos espécies apresentam morfologias fossoriais semelhantes (e independentes, do ponto de vista filogenético) que podem ter se originado a partir de mecanismos de desenvolvimento comuns, mostrando uma certa direcionalidade das pressões seletivas que agem sob os possíveis caminhos de desenvolvimento.

Este trabalho analisa o desenvolvimento dos embriões de cinco espécies da tribo Gymnophthalmini (Procellosaurinus tetradactylus, Vanzosaura rubricauda, Psilophthalmus paeminosus, Nothobachia ablephara e Calyptommatus sinebrachiatus), estabelecendo critérios para a determinação de estágios embrionário a partir da morfologia externa e analisando o desenvolvimento dos elementos de sustentação do crânio e dos esqueletos axial e apendicular de forma comparada, relacionando a morfologia ao hábito de vida. O hábito fossorial impõe pressões significativas ao corpo do animal, que apresenta modificações osteológicas para suportar tais pressões, como um crânio robusto, com elementos organizados de forma a proteger o encéfalo dos impactos da locomoção subterrânea, corpo alongado adaptado à locomoção por movimentos ondulatórios e membros reduzidos que não participam ativamente da movimentação. Também são apresentados dados preliminares sobre os possíveis processos responsáveis pela redução dos membros e pelo alongamento do corpo nas espécies fossoriais, relacionando as modificações do desenvolvimento à evolução do plano corpóreo serpentiforme. 


\begin{abstract}
The evolutionary history of the Gymnophthalmini (Gymnophthalmidae) is characterized by morphological modifications related to the evolution of a snake-like body plan adapted to fossorial habits. Fossorial snake-like species show adaptations, especially body lengthening and limb reduction, that are frequently observed throughout Squamate lineages.

Pattern formation is coordinated by a complex regulation network that acts during embryonic development, and subtle changes to this network may result in drastic phenotypic modifications, leading to evolutionary variation in body plans.

In this context, Squamates represent an excellent research model since several distant related species show similar (and phylogenetically independent) adaptations to fossoriality, which may have originated trhough common developmental mechanisms, and can reflect, to some extent, a predominance of certain selective pressures acting upon developmental pathways.

This work analyses the morphological aspect of embryonic development of five Gymnophthalmini species (Procellosaurinus tetradactylus, Vanzosaura rubricauda, Psilophthalmus paeminosus, Nothobachia ablephara e Calyptommatus sinebrachiatus) establishing criteria for the embryonic staging through external morphology, and analysing the development of cartilage and bone in the skull, and axial and appendicular systems in a comparative background, associating morphology to life habits. Fossorial life exerts great pressure upon the body, which demands an adaptative response in order to overcome this sort of impact. Thus, fossorial animals shows a robust skull, with bones tightly articulated as to protect the brain and sense organs, an elongated body for ondulatory locomotion and reduced limbs that do not actively participate in locomotion. Preliminary data on the possible developmental processes responsible for limb reduction and body elongation in the fossorial lineage are shown, and are discussed on the light of evolutionary developmental biology.
\end{abstract}




\section{CAPÍTULO 1 \\ INTRODUÇÃO}

\subsection{HISTÓRICOS}

\subsubsection{Família Gymnophthalmidae}

A região das dunas interiores do Rio São Francisco vem sendo alvo de intensa pesquisa desde a década de 80, após a descoberta de uma nova e peculiar fauna de Squamata caracterizada por possuir marcantes adaptações morfológicas à vida fossorial e psamófila (Rodrigues, 2002). Até então, supunha-se que a fauna herpetológica da caatinga era muito bem conhecida quando comparada a dos os outros domínios morfoclimáticos do Brasil (Ab’Saber, 1977; Vanzolini et al., 1980). No entanto, os estudos ali desenvolvidos revelaram uma fauna muito distinta da já descrita para a região das Caatingas, diversa, e com um grau de endemismo local não comparável a nenhum outro local da América do Sul (Rodrigues, 1996).

Nos últimos 12 anos, quatro gêneros e 22 espécies de Squamata foram descritas para a pequena área estudada nas proximidades das margens do São Francisco (Rodrigues, 1991a, b, c, 1993a, b; Vanzolini, 1991a, b; entre outros). Algumas espécies, em especial os lagartos, mostram adaptações à vida noturna e arenícola semelhantes à de muitas espécies típicas de desertos (Pianka, 1986). Além disso, áreas de habitats arenosos adjacentes ao local de estudo apresentam a fauna característica das caatingas, descrita principalmente por Vanzolini e colegas (1980), com poucos endemismos e geralmente sem espécies com adaptações tão acentuadas à psamofilia como as encontradas na área das dunas (Rodrigues, 1996, 2002).

Grande parte desta nova fauna é representada por pares de espécies alopátricas vicariantes, que sofreram especiação possivelmente após a mudança de curso do Rio São Francisco, no Quaternário. De acordo com o modelo originalmente proposto por Rodrigues (1991a), o padrão de drenagem exorréica do rio seria recente e poderia ter atuado como uma barreira natural, separando e isolando as populações ancestrais das espécies de lagartos, serpentes e anfisbenas em margens opostas. O histórico geológico e a presença desta fauna distinta acabaram por direcionar estudos multidisciplinares sobre a evolução dos diferentes grupos ali presentes (Benozzatti \& Rodrigues, 2003; Martins, 1997; Pellegrino et al., 1999a, b, 2001; Renous et al., 1995, 1999; Rocha, 1998; Rodrigues, 1995, 1996; 2002; Rodrigues \& Juncá, 2002; Yonenaga-Yassuda e Rodrigues, 1999).

Em relação à fauna de lagartos psamófilos e fossoriais, grande parte das espécies endêmicas pertence à família Gymnophthalmidae (Estes et al., 1988), que é composta por 42 gêneros de 
pequenos lagartos que apresentam ampla distribuição geográfica (Rodrigues et al., 2009).

A elucidação das relações filogenéticas da família Gymnophthalmidae foi um grande passo para os estudos evolutivos dos grupos reconhecidos taxonomicamente dentro desta família (Pellegrino et al., 2001). A grande incidência de modificações morfológicas semelhantes relacionadas à fossorialidade e à psamofilia em espécies dos diferentes grupos da família sempre representou uma grande dificuldade nas tentativas de se estabelecer as relações de parentesco. Importantes descrições e revisões foram feitas sobre os microteídeos (Presch, 1980; Estes et al., 1988; Rodrigues, 1991a, b, e c; entre outros), mas não havia, até então, sido formulada uma proposta convincente sobre as relações filogenéticas de todos os Gymnophthalmidae devido à essa ocorrência generalizada de convergências.

O estudo de Pellegrino et al. (2001) reconstruiu a história filogenética da família a partir de análises de dados moleculares, reconhecendo então as seguintes subfamílias: Alopoglossinae, Rhachisaurinae, Gymnophthalminae, com duas tribos, Gymnophthalmini e Heterodactylini, e Cercosaurinae, também reunindo duas tribos, Cercosaurini e Ecpleopini.

A nova proposta filogenética mostrou que as diversas adaptações morfológicas representam modificações convergentes, que foram adquiridas independentemente em várias linhagens da família Gymnophthalmidae e cujo grau de desenvolvimento varia enormemente entre as espécies. Essas adaptações incluem modificações para uma forma serpentiforme, como o alongamento do corpo, a redução/perda dos membros, a perda de pálpebras e a de ouvido externo (Pellegrino et al., 2001; Rodrigues et al., 2005). Além disso, a redução de membros dentro da família mostra dois padrões distintos: nos Gymnophthalmini a redução apendicular é mais acentuada nos membros anteriores, padrão este que mostra a mesma tendência ocorrida na evolução das serpentes; nos Cercosaurini a redução é mais acentuada nos membros posteriores, evidenciando um padrão similar ao observado nos anfisbenídeos (Rodrigues, 1995; Pellegrino et al., 2001).

Ainda, outros aspectos da biologia dos Gymnophthalmidae, como a ampla distribuição geográfica, ocorrendo desde áreas abertas dos Andes até florestas tropicais ao nível do mar, a presença de espécies semiaquáticas (Neusticurus e Potamites) e partenogenéticas (Gymnophthalmus e Leposoma) e a grande variação cromossômica, com número diplóide entre 2n=32 e 2n=64 (Cole et al., 1990; Yonenaga-Yassuda et al., 1995, 1996a; Pellegrino, 1998; Yonenaga-Yassuda e Rodrigues, 1999 Pellegrino et al. 1999a, b; entre outros) fazem desta família um importante e rico modelo para estudos evolutivos e filogenéticos.

O estudo de Pellegrino et al. (2001) também comprovou o monofiletismo da tribo Gymnophthalmini, já anteriormente proposto por Rodrigues (1995) com base em um estudo de caracteres morfológicos (osteologia, morfologia externa e anatomia do hemipênis). Até 2008, a tribo era 
composta por 8 gêneros de pequenos lagartos: Tretioscincus, Micrablepharus, Gymnophthalmus, Procellosaurinus, Vanzosaura, Psilophthalmus, Nothobachia e Calyptommatus; os três primeiros (Tretioscincus, Micrablepharus e Gymnophthalmus) são característicos da Amazônia e Brasil central, Vanzosaura tem distribuição mais ampla e os restantes (Procellosaurinus, Psilophthalmus, Nothobachia e Calyptommatus) são endêmicos da região de dunas do São Francisco (Rodrigues, 1995). Em 2008 foi descrito um novo gênero fossorial e sem pálpebras desta irradiação (Rodrigues e dos Santos, 2008) do Parque Nacional do Catimbau, nas caatingas de Pernambuco, Brasil, à uma distância aproximada de $300 \mathrm{Km}$ à nordeste das dunas arenosas onde Calyptommatus e Nothobachia são encontrados. Scriptosaura catimbau tem corpo alongado, não apresenta membros anteriores e os posteriores são reduzidos à apêndices estiliformes e foi considerado preliminarmente como irmão do gênero Calyptommatus, diferindo deste por características externas, como ausências de escama ocular e de uma escama temporal aumentada, ambas sinapomorfias características de Calyptommatus (Rodrigues e dos Santos, 2008).

A tribo Gymnophthalmini é marcada por espécies com padrões corpóreos lacertiformes e serpentiformes e a história evolutiva destas espécies mostra uma forte tendência relacionada à transição de formas lacertiformes para formas serpentiformes, formando uma sequência de morfologias com adaptações progressivas à fossorialidade. Os três gêneros mais basais, Procellosaurinus, Vanzosaura e Psilophthalmus, apresentam corpo não alongado e mais curto em relação ao tamanho da cauda, e membros anterior e posterior bem desenvolvidos, com quatro e cinco dígitos respectivamente. Já em Nothobachia, Scriptosaura e Calyptommatus, os mais derivados da radiação, são observados os casos mais extremos de modificações morfológicas nos caracteres relacionados à vida serpentiforme, com alto grau de alongamento do corpo e de redução de membros, redução do olho e perda do ouvido externo. Em relação aos membros, Nothobachia possui um membro anterior estiliforme (com um único dígito) e o posterior com apenas dois dígitos; Scriptosaura e Calyptommatus, por sua vez, não apresentam membro anterior externo no adulto e possuem membros posteriores estiliformes, com um único dígito. Nestes três gêneros, o ouvido externo é coberto por uma escama auditiva e a pálpebra está ausente, sendo que apenas em Calyptommatus, há a diferenciação de uma escama ocular cobrindo o olho (Rodrigues, 1991c; Pellegrino et al., 2001). Calyptommatus ainda apresenta outras modificações morfológicas expressivas (caracteres únicos na história da família), como a presença de um palato secundário e de um jugal trirradiado, além de ossos dérmicos do crânio e columela altamente modificados (Rodrigues, 1995). Ainda, estes lagartos apresentam um desenvolvimento embrionário acelerado em relação aos demais lagartos (de aproximadamente 30-45 dias, enquanto que o tempo de desenvolvimento da maioria dos lagartos varia de 2-6 meses; Vitt, 1995). 
A linhagem dos Gymnophthalmini é bastante recente, com origem estimada há aproximadamente 7-8 milhões de anos, e a radiação dos gêneros endêmicos da região das dunas do São Francisco é estimada como tendo surgido há 2-3 m.a. (Benozzati e Rodrigues, 2003). A drástica mudança de planos corpóreos entre estas espécies, ocorrida neste curto período de tempo, faz deste grupo um ótimo modelo para estudos relacionando os mecanismos atuantes no desenvolvimento embrionário e o surgimento das modificações evolutivas, como a redução apendicular, o alongamento do corpo e outras adaptações osteológicas e fisiológicas, levando à modificação de um plano corporal lacertiforme básico em um plano serpentiforme. A investigação dos possíveis processos do desenvolvimento que podem ter sido responsáveis por estas modificações morfológicas neste grupo fornecerá bases para a análise evolutiva de eventos de transição morfológica semelhantes, como os observados em outros grupos de lagartos e nas serpentes.

\subsubsection{Biologia Evolutiva do Desenvolvimento}

A busca pela compreensão dos mecanismos de formação do organismo é bastante antiga. Documentos egípcios e sânscritos já continham descrições de embriões, mas foi Aristóteles, no século 4AC, o primeiro a realizar estudos embriológicos de maneira sistemática. Descreveu o desenvolvimento do embrião de galinha e de outras espécies de animais e identificou os diferentes tipos pelos quais os animais nascem (oviparidade, viviparidade e ovoviviparidade), os dois grandes padrões de clivagem embrionária (holoblástica e meroblástica) e as funções da placenta e do cordão umbilical (Gilbert, 2006).

A invenção do microscópio permitiu observações mais detalhadas sobre o desenvolvimento embrionário. O primeiro trabalho relevante após Aristóteles veio em 1672, quando Marcello Malpighi publicou um trabalho descritivo sobre o desenvolvimento de embriões de galinha no qual identificou estruturas como a fenda neural, os somitos e o sistema circulatório embrionário (Gilbert, 2006).

A partir do século 19 ocorreu uma revolução no estudo da embriologia e, durante este período, muitos nomes da ciência se destacaram, entre eles Karl Ernst von Baer, Richard Owen e Ernst Haeckel. A partir de extensos estudos comparativos com séries ontogenéticas de embriões de vertebrados, von Baer, em 1828, e Haeckel, em 1866, com sua Lei Biogenética, fizeram importantes observações sobre o desenvolvimento embrionário e sua relação com a origem/existência de planos corpóreos comuns a grupos de animais (Richardson e Keuck, 2002).

Richard Owen, por volta de 1840, deu uma perspectiva evolutiva às idéias de von Baer, discutindo as questões de homologia e analogia com base no desenvolvimento embrionário (Hall, 1992) e utilizando os conceitos de von Baer para mostrar a existência de um plano de desenvolvi- 
mento comum à cada grupo de animais, de onde resultava sua morfologia típica e de onde eram derivadas as modificações (Hall, 1992). As idéias de Owen, unindo os problemas evolutivos à ontogenia, voltaram a atenção dos morfologistas da época para o desenvolvimento embrionário.

A partir de então, a embriologia passou a representar o caminho para a compreensão das relações filogenéticas e o estudo dos embriões passou a ser visto como a melhor evidência para se determinar homologias; o conceito começou, então, a ser aplicado com base no desenvolvimento e não mais com base nas estruturas adultas e suas conexões (Hall, 1992). Assim, a embriologia comparada transformou-se na embriologia evolutiva à medida que questões com viés filogenético foram incorporadas e tomaram força nas discussões sobre o desenvolvimento (Gilbert, 2003).

A idéia de ancestralidade explicando a existência e o compartilhamento dos planos de desenvolvimento comuns a grupos de organismos veio com a Teoria da Evolução de Darwin. A ancestralidade comum forneceu a explicação para a homologia e os conceitos de hereditariedade e adaptação foram usados para explicar mudanças na morfologia ao longo do tempo. O arcabouço teórico do final do século 19 estava, portanto, estabelecido: um cenário de grandes idéias e especulações marcado por tentativas de se estabelecer uma teoria evolutiva integrando as idéias de citologia, embriologia, filogenia e evolução (Buss, 1987).

Porém, no final de 1920 e início de 1930, houve uma separação entre genética e embriologia; a genética foi redefinida como a ciência que estudava a transmissão de características hereditárias, enquanto a embriologia estudava apenas a expressão destas características. A redescoberta das idéias de Mendel fortaleceu a busca pelas estruturas responsáveis pela transmissão de caracteres hereditários e experimentos nesta área avançaram muito. Com a união das idéias de Mendel e de Darwin, a evolução das espécies poderia ser totalmente explicada pela produção randômica de mutações gênicas e pelo ambiente que agia de modo a selecionar os fenótipos mais adaptados (www.devbio.com), fornecendo, assim, um forte modelo para o surgimento dos fenômenos evolutivos. A embriologia, por sua vez, não dispunha de nada que pudesse substituir a visão de evolução fortemente embasada pelos estudos genéticos e focou-se, então, no desenvolvimento do seu campo experimental (Gilbert et al., 1996; Gilbert, 2006).

A genética cresceu como ciência, com interesses focados na frequência de expressão de caracteres ao longo das gerações, sem se preocupar com a maneira que estes caracteres eram expressos (Buss, 1987), e os embriologistas, por outro lado, voltaram a atenção para a identificação de relações de causa e efeito na ontogenia, deixando de lado o enfoque filogenético (Buss, 1987). Assim, as duas ciências entraram em divergência e permaneceram separadas ao mesmo tempo em que se desenvolviam como ciências experimentais (Gilbert, 2006).

Perto da década de 40 vieram algumas tentativas de reintegração com Gluecksohn-Schoe- 
nheimer e Waddington, mostrando a existência de algumas mutações afetando o desenvolvimento embrionário, e com Goldschimidt, que acreditava fortemente que a evolução era o resultado de mudanças herdáveis no desenvolvimento; no entanto, isso não foi suficiente para reaproximar os dois campos de estudo. A relutância dos embriologistas em aceitar a genética mendeliana (Mayr, 1993) teve um efeito profundo no desenvolvimento da teoria evolutiva: a Teoria Sintética da Evolução foi elaborada sem a participação dos embriologistas (Buss, 1987) e não via necessidade de nada além da seleção natural e da genética de populações (Wagner e Laubichler, 2004).

Porém, na segunda metade do século 20, alguns pesquisadores iniciaram novas tentativas de ampliar a Teoria da Evolução para incluir perspectivas macroevolutivas e do desenvolvimento (Wagner e Laubichler, 2004), como C.H. Waddington e G.R. de Beer (Embryos and Ancestors, 1951), por exemplo. O começo da reaproximação das duas ciências veio pela percepção de que ambas são complementares: enquanto o enfoque da genética de populações é na sobrevivência do mais apto, o enfoque da genética do desenvolvimento é de como surgiu este "mais apto" (www. devbio.com).

Mas foi por volta da década de 80 que essas tentativas realmente tomaram força, com a publicação de diversos livros e trabalhos dando um enfoque evolutivo à biologia do desenvolvimento e revolucionando a biologia evolutiva (Wagner e Laubichler, 2004). Podem ser citados pesquisadores como S.J. Gould, com o livro Ontogeny and Phylogeny (1977); R. Riedl, com Order in Living Organisms: a Systems Analysis of Evolution (1978); R.A. Raff e T.C. Kaufman, com Embryos, Genes and Evolution (1983); W. Arthur, com Mechanisms of Morphological Evolution (1984); K.S. Thomson, com Morphogenesis and Evolution (1988); B.K. Hall, com Evolutionary Developmental Biology (1992); entre outros. Além disso, a descoberta dos genes homeóticos e da sua universalidade e alto grau de conservação entre os animais, evidenciando profundas implicações para a evolução dos padrões e processos do desenvolvimento, foi o marco definitivo da reintegração da biologia evolutiva e da biologia do desenvolvimento (Arthur, 2002). Esta descoberta, aliada ao desenvolvimento da biologia molecular e de novas técnicas, foi essencial para que a biologia do desenvolvimento ganhasse aspecto teórico relevante para a compreensão dos mecanismos evolutivos e dos padrões históricos revelados pelos estudos filogenéticos e paleontológicos (Raff, 2000).

A Biologia Evolutiva do Desenvolvimento (Hall, 1992; também chamada EvoDevo) surge, portanto, a partir da percepção de que o desenvolvimento pode contribuir de maneira crucial à compreensão dos processos evolutivos e, deste modo, propõe um novo modelo de evolução que integra a genética do desenvolvimento e a genética de populações, além de áreas como a paleontologia, morfologia e ecologia (Robert, 2002), para explicar e definir o surgimento e a diversidade 
de formas (Hall, 2000; Gilbert, 2006). A união destas ciências em uma nova disciplina possibilita desvendar fenômenos e prover explicações antes inacessíveis ao arcabouço teórico de cada uma (Robert, 2002).

O princípio fundamental da EvoDevo está baseado na proposição de que a evolução é causada por mudanças herdáveis no desenvolvimento (von Dassow e Munro, 1999; Raff, 2000; Robert, 2002; Gilbert, 2006) e preocupa-se em analisar e compreender os mecanismos do desenvolvimento envolvidos na construção do organismo que levam à modificações evolutivas nos fenótipos (Goodman e Coughlin, 2000; Hall, 2003). Em outras palavras, tudo que está entre o genótipo e o fenótipo é assunto da biologia evolutiva do desenvolvimento (Hall, 1992; Raff, 2000; Arthur, 2002; Hall, 2000 e 2003; Love, 2003, entre outros). Desta maneira, o problema central da EvoDevo é entender como o processo de desenvolvimento está arquitetado e como essa disposição - e variações nestas configurações - permite variações evolutivas ao sistema.

Neste sentido, um dos princípios fundamentais para a compreensão dos processos que medeiam a transformação do genótipo no fenótipo é o de que o desenvolvimento é modular e hierárquico (Buss, 1987; Thomson, 1988; Gilbert et al., 1996; Hall, 1992, 2000 e 2003; Bolker, 2000; Raff e Sly, 2000) e, portanto, resultante de interações entre os diversos componentes envolvidos nos processos.

A modularidade implica a existência de subunidades básicas autônomas que podem ser definidas em diferentes níveis de organização (genético, celular, tecidual, fisiológico, etc), níveis estes que representam conjuntos definidos de características ou interações conservadas ao longo do processo evolutivo (Bolker, 2000; Raff e Raff, 2000; Raff e Sly, 2000; Hall, 2003; Poe, 2004; Gilbert, 2006, entre outros). A característica modular impõe limites ou restrições ao desenvolvimento, pois determinados módulos podem estar tão integrados que sua dissociação pode ser bastante difícil (Raff, 2000; Raff e Sly, 2000). A existência destas “configurações evolutivamente estáveis”, ou seja, fortes e importantes interações entre as partes do sistema, resultam na fixação das interações (estabilização do ponto de vista evolutivo) devido ao alto grau de interdependência (Kavanagh, 2003) e, deste modo, a pressão de seleção sob determinado elemento demanda a resposta de outro(s) elemento(s) de forma a manter a relação funcional entre eles. Portanto, a resistência de tal sistema altamente integrado a qualquer mudança evolutiva é bastante grande.

Ao mesmo tempo em que existe esta alta restrição de elementos às opções dos sistemas de desenvolvimento, a propriedade modular também é uma grande fonte de mudanças evolutivas (Maynard Smith et al., 1985; Bolker, 2000; Raff, 2000; Raff e Sly, 2000; Gilbert, 2006), já que dissociações entre módulos podem acontecer e podem levar à introdução de variações viáveis nos padrões de desenvolvimento (Thomson, 1988; Gilbert et al., 1996; Raff, 2000; Raff e Sly, 2000). 
Um dos principais fatores de dissociação entre elementos dos sistemas em desenvolvimento são os procesos heterocrônicos (dissociação no tempo; de Beer, 1951; Gould, 1977; Hall, 1984; Raff, 1996; Raff, 2000; entre outros); os processos de duplicação e divergência e co-opção também são importantes processos que podem levar à introdução de variação nos sistemas (Hall, 1992; Raff, 1996; Gilbert, 2006).

O processo do desenvolvimento também tem um forte componente ambiental. Todo sistema em desenvolvimento interage com o ambiente no qual se desenvolve, que pode representar desde o meio celular até o ambiente externo; desta forma, tais sistemas são extremamente dependentes das condições ambientais nas quais estão inseridos. Esta característica do desenvolvimento é a epigenética e, de acordo com Hall (1992), os mecanismos epigenéticos representam a conjunção de fatores genéticos e não-genéticos agindo nos diversos níveis organizacionais do sistema de desenvolvimento, controlando seletivamente a expressão de genes ou a dissociação entre os tempos de expressão destes genes para a produção das variantes fenotípicas.

É exatamente devido à existência e necessidade intrínseca de interações entre partes que se observa a não-correspondência entre genótipo-fenótipo e que se pode estabelecer, por conseguinte, os mecanismos epigenéticos hierárquicos do desenvolvimento como a principal causa de introdução de variação no nível evolutivo. E é a partir do estudo destas inter-relações que a biologia evolutiva do desenvolvimento pretende abordar questões referentes ao desenvolvimento individual propriamente dito (diferenciação, morfogênese, crescimento) e também como as variações nos processos do desenvolvimento ao longo do tempo foram possíveis nos níveis micro e macroevolutivo de forma a gerar diversidade de planos corporais.

\subsection{ASPECTOS MORFOLÓGICOS DO DESENVOLVIMENTO EMBRIONÁRIO}

O desenvolvimento embrionário é o processo de construção do organismo (Thomson, 1988) a partir de uma sequência de estágios organizados temporalmente. A formação de um organismo depende da diferenciação, estruturação e organização de grupos de células em tecidos e órgãos funcionais que são capazes de interagir entre si (Gilbert, 2006).

A formação de padrão durante o desenvolvimento é controlada por mecanismos conservados e compartilhados por vários grupos (Slack et al., 1993) e modificações nestes padrões são as principais causas responsáveis pela variação morfológica observada entre as espécies (Richardson et al., 1999).

Nesta seção são apresentadas descrições sobre os processos de organização e construção 
dos elementos de sustentação embrionários, elaboradas com bases nas detalhadas descrições de de Beer (1937), Romer (1956), Bellairs e Kamal (1981), Russel e Bauer (2008) e Evans (2008), entre outros, e sobre os mecanismos moleculares que regem o desenvolvimento dos membros.

\subsubsection{Origem embrionária do esqueleto}

O esqueleto dos vertebrados é um dos sistemas mais importantes para estudos morfológicos. A estrutura mineralizada dos ossos (e menos frequentemente de cartilagens) é preservada em fósseis, permitindo comparações com grupos viventes e a determinação de homologias, com o objetivo de traçar as relações entre os diferentes grupos. As grandes variações dos elementos esqueléticos, observadas ao longo da história evolutiva dos grandes grupos, refletem a plasticidade de tal sistema para responder aos diferentes habitats dos animais, fornecendo informações importantes a respeito do modo de vida do animal, como postura, porte, tipo de locomoção, alimentação, entre outras.

Os padrões de desenvolvimento das cartilagens e ossos mostram os mecanismos responsáveis pela origem destas variações evolutivas, e são importantes indícios de relações de parentesco (Maisano, 2002).

Os elementos do esqueleto são provenientes do tecido mesodérmico do embrião. A mesoderme embrionária é dividida em três grandes partes (figura 1.1): a mesoderme paraxial (localizada imediatamente aos lados do tubo neural), da qual se formam os somitos que, por sua vez, originam diversas outras estruturas, como vértebras, costelas, músculos e partes de alguns dos elementos das cinturas; a mesoderme lateral (mais externa), da qual originam-se, entre outras estruturas, elementos esqueléticos dos membros e os músculos associados; e a mesoderme intermediária, que origina o sistema urogenital.

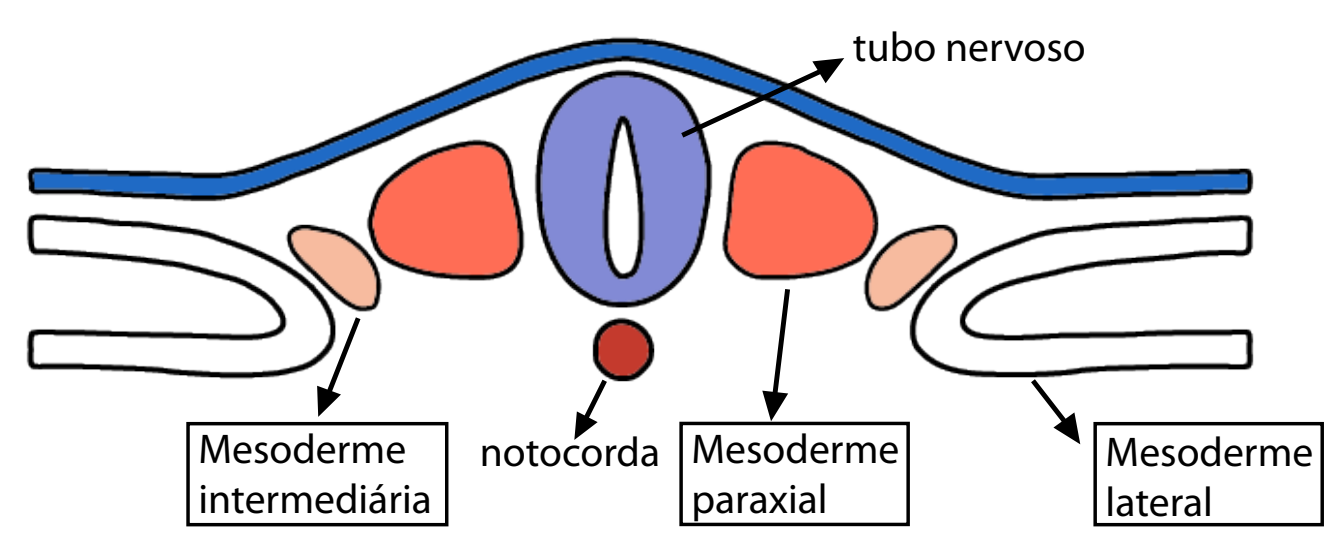

Figura 1.1. Os componentes da mesoderme embrionária; corte transversal na altura do tronco. Modificado de Gilbert (2006). 
Os somitos são blocos de células mesodérmicas (figura 1.2A e B) que se formam simultaneamente ao fechamento do tubo neural, com a divisão progressiva, no sentido antero-posterior, da mesoderme paraxial. Os somitos maduros são divididos em três compartimentos (figura 1.2C): a região mais ventral é chamada de esclerótomo e dá origem às cartilagens das vértebras e costelas; os outros dois compartimentos são o dermátomo (mais dorsal, origina a derme) e o miótomo (forma a musculatura das costas, costelas e membros).

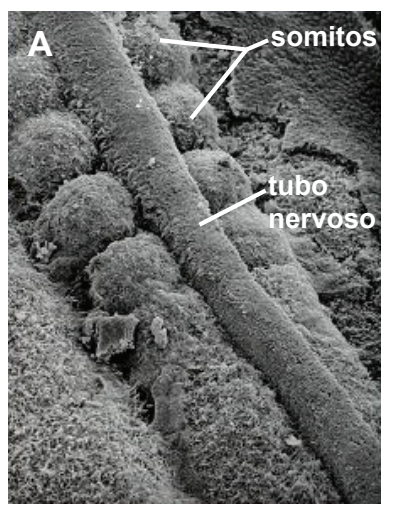

\section{B}
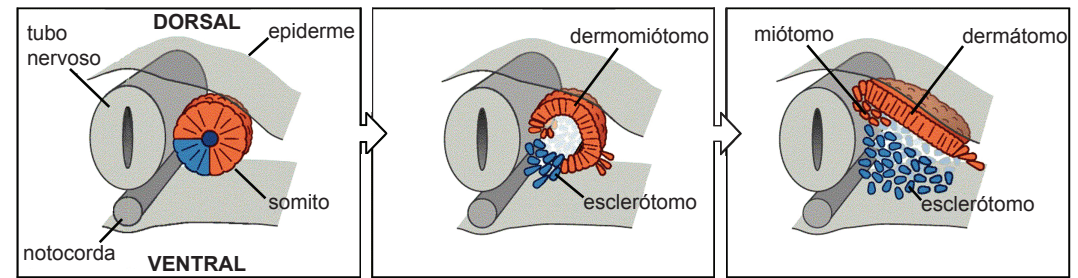

Figura 1.2. Formação e maturação dos somitos. A. Fotomicrografia mostrando a formação dos somitos aos lados do tubo nervoso. B. Esquema mostrando a maturação dos somitos. Modificado de Gilbert (2006).

Os elementos cranianos têm origem diferente. Elementos derivados dos arcos faríngeos são originados de células da crista neural; os demais elementos dérmicos e endocondrais têm origem mista, com a parte anterior do crânio derivando de células da crista neural e a parte posterior de uma combinação de células da crista neural e de células mesodérmicas (Jiang et al., 2002).

\subsubsection{Tecidos de sustentação}

\section{Notocorda}

A primeira estrutura de sustentação do embrião é a notocorda, formada durante a neurulação com o fechamento do tubo nervoso dorsal; fica localizada ventral a este. Nos adultos, a coluna vertebral substitui a notocorda, que persiste como uma estrutura residual formando os discos intervertebrais.

\section{Cartilagem}

Tem origem mesodérmica ou ectodérmica (quando originado a partir da crista neural) e é composta por condrócitos embebidos numa matriz extracelular fibrosa. A cartilagem é o tecido mais importante do ponto de vista embriológico, pois durante a maior parte do desenvolvimento toda a sustentação do embrião é feita por estruturas cartilaginosas; além disso, a flexibilidade do tecido permite o aumento de tamanho sem que a forma da estrutura se modifique, preservando 
conexões com outros elementos esqueléticos ou musculares.

\section{Osso}

O tecido ósseo contém alta concentração de fibras e de cálcio organizadas numa rede com padrão muito bem definido em relação às lacunas deixadas pelos osteócitos; tal arranjo faz com que o osso seja menos flexível que a cartilagem (pois não pode se expandir), mas muito mais forte e resistente. O esqueleto dos vertebrados é composto por ossos do tipo dérmico e do tipo endocondral.

Os ossos dérmicos são os ossos nos quais o processo de ossificação ocorre diretamente a partir de uma densa matriz de tecido conjuntivo, que é formada nas regiões mais profundas da derme; são mais frequentes no crânio e na cintura escapular.

Os ossos do tipo endocondral são formados a partir de um molde cartilaginoso. A ossificação se inicia por um fino revestimento de osso membranoso depositado ao redor do periósteo, a membrana que delimita o molde cartilaginoso. Assim, espículas ósseas começam a invadir o molde cartilaginoso e substituir gradualmente a matriz cartilaginosa. Ao mesmo tempo em que ocorre a substituição por osso, o crescimento da cartilagem continua, de forma que as extremidades dos elementos permanecem cartilaginosas; tal dinâmica persiste por um tempo no juvenil até que todo o molde esteja ossificado por completo. Grande parte do diâmetro do osso aumenta principalmente pela deposição de camadas ósseas membranosas principalmente na região mediana do elemento (ossificação pericondral), ao invés de ser o reflexo apenas do molde cartilaginoso. Os ossos endocondrais são geralmente os ossos longos do esqueleto (ossos dos membros), os que compõem o condrocrânio, as vértebras e outros elementos das cinturas escapular e pélvica.

\subsubsection{Padrão geral do desenvolvimento do esqueleto craniano e axial de Squa-} mata

\section{Crânio}

O crânio é formado por uma proteção endocondral (o condrocrânio) mais interna, e um revestimento dérmico (dermatocrânio), externo. Além destes, também estão presentes elementos endocondrais derivados dos arcos faríngeos.

Desenvolvimento do condrocrânio: o condrocrânio é definido como a porção do crânio que é cartilaginosa em algum momento da vida do animal (Bellais e Kamal, 1981). Os elementos derivados de tecido cartilaginoso estão localizados principalmente na região posterior do crânio, próximos ou envolvendo as cápsulas óticas e a maior parte do encéfalo, e nas cartilagens da cápsula nasal e da região orbitotemporal. Alguns elementos derivados do esqueleto visceral 
(cartilagem palatoquadrada, cartilagem de Meckel e aparelho hióide) estão associados ou incorporados a elementos do condrocrânio e, por este motivo, também são considerados componentes do mesmo.

A região posterior é a primeira a ser formada durante o desenvolvimento do crânio, inicialmente com elementos que sustentam o encéfalo ventralmente e depois com o crescimento de estruturas ao redor das cápsulas óticas que fornecem proteção lateral. Nesta fase, quando se desenvolvem as primeiras estruturas cartilaginosas, o encéfalo já está bastante desenvolvido. A proteção dorsal da parte posterior do encéfalo é a mais tardia.

O primeiro elemento componente do condrocrânio propriamente dito é um par de barras cartilaginosas ventrais chamadas paracordais; tais barras flanqueam a notocorda e se fundem rapidamente dando origem a uma placa única chamada placa basal (figura 1.3); nos Squamata, a placa basal já surge como uma placa única (Kamal, 1966a). A fenestra basicranial anterior é delimitada pelas margens laterais e posterior da placa basal e pela cartilagem acrocordal anterior. A extremidade anterior da notocorda fica embebida na cartilagem da placa basal.

Outro par de barras cartilaginosas se desenvolve para compor a região ventral mediana e anterior do crânio, as trabéculas. Tais barras se estendem antero-posteriormente no crânio, desde a região nasal até a frente da placa basal. Surgem já fundidas anteriormente em um bastão único (trabécula comum), formando a base dos septos nasal e interorbital (condição tropibásica; de Beer, 1937) e divergem posteriormente próximo ao condrocrânio (figura 1.3), fundindo-se, subsequentemente, às extremidades laterais da cartilagem acrocordal. A fenestra triangular delimitada entre as extremidades da trabécula e a cartilagem acrocordal é denominada fossa pituitária. Em cada extremidade da trabécula desenvolve-se, lateralmente, um processo basipterigóide.

Na região posterior do crânio desenvolvem-se os arcos pré-occipitais (normalmente 3 pares de arcos), que são serialmente homólogos aos arcos neurais das vértebras (Romer, 1956), e entre cada arco emergem as raízes do nervo hipoglosso. Estes arcos logo se fundem numa estrutura única, o arco occipital, deixando três pequenos forâmens para a saída dos ramos deste nervo. Logo em seguida, o arco occipital funde-se à margem posterolateral da placa basal (figura 1.3). 


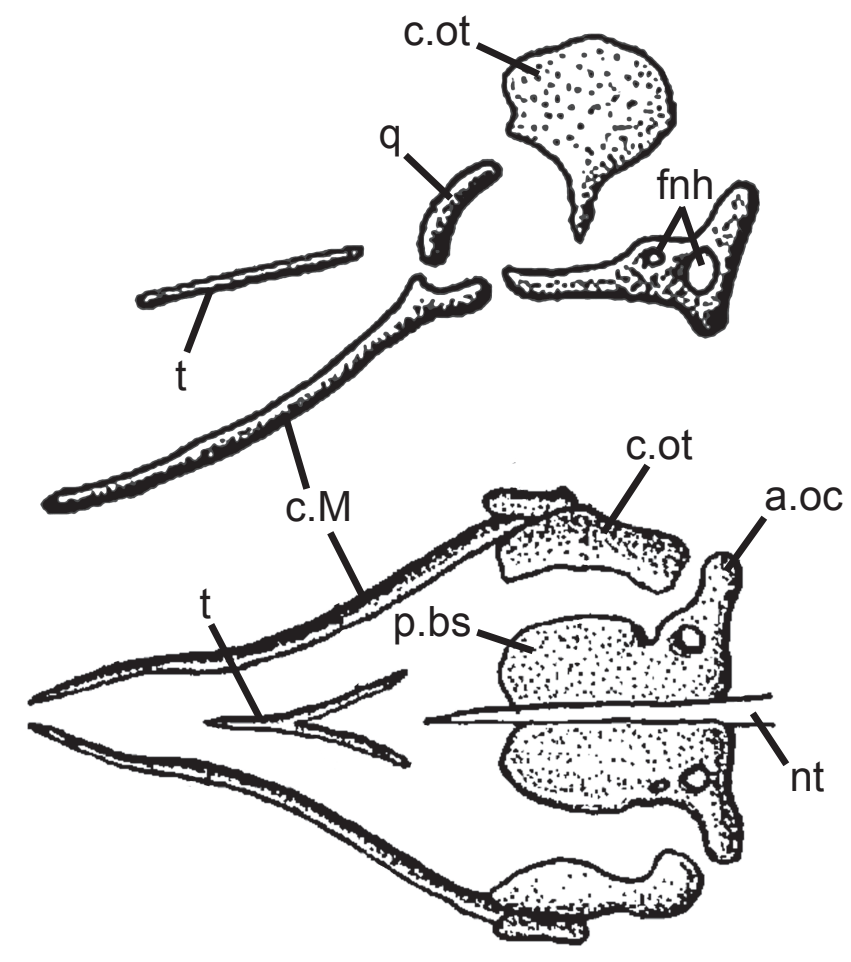

Figura 1.3. Esquema do crânio no início do desenvolvimento, em vistas lateral (acima) e dorsasl (abaixo), mostrando o padrão geral dos elementos de sustentação no início do desenvolvimento. Modificado de de Beer (1937).

Formam-se, ainda, um par de cápsulas óticas cartilaginosas que se desenvolvem na região lateral e posterior, ao redor das estruturas nervosas do labirinto. As cápsulas óticas têm inicialmente a forma de concha, englobando as estruturas do ouvido interno, e formando a parede lateral do condrocrânio; pouco tempo depois, distingue-se a fenestra ovalis (fenestra vestibular), à qual a columela está inserida, na parede lateral da cápsula. Em fases posteriores desenvolve-se o teto sinótico, cartilaginoso, unindo as cápsulas óticas dorsalmente.

A cápsula ótica é inicialmente separada do complexo formado pela placa basal e arco occipital por uma fenda, a fissura metótica. O primeiro contato entre a cápsula ótica e a placa basal ocorre com a fusão anterior destas duas estruturas; este primeiro ponto de fusão é denominado comissura basicapsular. A comissura prefacial, anterior à primeira, forma-se logo depois, envolvendo o nervo facial. Com o crescimento do arco occipital e da cápsula ótica, ocorre o contato entre a ponta dorsal do primeiro com a parede posterior da cápsula, fechando a fissura metótica dorsalmente.

Esta fissura é dividida subsequentemente pela aposição da parede posterior da cápsula ótica (proeminência ampular posterior; Kamal, 1971) ao arco occipital, formando, antero-ventralmente, a abertura lateral do recessus scalae tympani, por onde passam o duto perilinfático e 
o nervo glossofaríngeo (IX) e, postero-dorsalmente, o forâmen jugular, por onde passa o nervo vago (X). Após a ossificação, o recessus scalae tympani forma o recesso occipital (Rieppel, 1985).

Na cartilagem da cápsula ótica diferenciam-se o proótico (anterior) e o otooccipital (posterior); este último é resultante da fusão entre o opistótico, elemento adjascente ao proótico, e o exoccipital, que representa o arco occipital ossificado. O exoccipital do adulto pode apresentar de um a três forâmens do nervo hipoglosso; fusões dos forâmens podem ocorrer durante o desenvolvimento dependendo do grupo ao qual o animal pertence.

Os canais semicirculares são observados na parede da cápsula ótica; na margem inferior do canal semicircular horizontal, entre proótico e opistótico, desenvolve-se a crista parótida, a partir da qual, após a ossificação, se formará o processo paroccipital, ao qual o quadrado se articula.

Da ossificação da placa basal forma-se o basioccipital, que protege grande parte da região ventral do encéfalo. À frente deste elemento forma-se o basisfenóide, originado da cartilagem acrocordal (que forma a crista sellaris) e das extremidades posteriores da trabécula; o processo basipterigóide, do osso basisfenóide, projeta-se lateralmente de cada extremidade posterior da trabécula e se articula com o pterigóide, osso dérmico da região palatal, formando um dos pontos de união entre condrocrânio e dermatocrânio. O parasfenóide é um osso dérmico delgado que se forma ventralmente ao basisfenóide e funde-se a ele; normalmente não é possível distinguir ou delimitar os dois e, por isso, o complexo geralmente é chamado de parabasisfenóide. Na região dorsal o supraoccipital se ossifica a partir do teto sinótico, sendo derivado, portanto, das cápsulas óticas.

Os otooccipitais formam as margens laterais do côndilo occipital e as margens laterais do forâmen magno. A parte ventral do côndilo, assim como a margem ventral do forâmen magno, são formadas pelo basioccipital. A margem superior do forâmen é formada pelo supraoccipital.

Nos adultos, o basioccipital está unido ao basisfenóide anteriormente, ao proótico antero-lateralmente e ao otooccipital postero-lateralmente. O parabasisfenóide funde-se ao proótico dorsalmente. As margens ventro-laterais do supraoccipital contatam o proótico anteriormente e o otooccipital posteriormente.

As cápsulas nasais protegem os sacos nasais e o órgão de Jacobson e são separadas medialmente pelo septo nasal. A narina é moldada pela cartilagem da cúpula nasal anterior, que se estende até a câmara olfativa posterior; a concha nasal constringe lateralmente a conexão entre a cúpula nasal e a câmara olfativa. O plano anteorbital delimita a margem posterior da câmara olfativa.

A cápsula nasal conecta-se às cartilagens interorbitais, que representam pontos de origem da musculatura oblíqua dos olhos, além de sustentarem os bulbos olfativos do prosencéfalo. $\mathrm{O}$ 
septo interorbital é contínuo ao septo nasal (Kamal, 1965d) e separa medialmente os globos oculares; este septo também é continuo posterodorsalmente com o plano supraseptal, representado por um par de "asas" projetadas dorsalmente, que sustentam os bulbos olfativos e conectam-se à cápsula nasal pelas comissuras esfenetimóides. Uma rede de barras cartilaginosas faz parte do condrocrânio: um par de tênias marginais dorsolaterais liga cada "asa” do plano supraseptal à cápsula ótica; um par de tênias mediais conecta as pilas metótica e antótica, também pareadas, e que, por sua vez, fazem a ligação transversal das cartilagens do condrocrânio. As extremidades ventrais das pilas metóticas encontram-se medialmente para formar a cartilagem hipoquiasmática, que se liga à trabécula comum, e, dorsalmente, ligam-se à tênia medial e ao plano supraseptal. A pila antótica conecta-se ventralmente à extremidade anterior da placa basal e a pila acessória conecta as tênias medial e marginal. O órbitosfenóide ossifica-se na região de contato entre as pilas antótica e metótica, e a tênia medial.

Os elementos derivados dos arcos faríngeos são representados pela cartilagem palatoquadrada, a cartilagem de Meckel, o aparelho columelar e o aparelho hióide. Da cartilagem palatoquadrada formam-se o quadrado, que faz a articulação do crânio com a mandíbula e o epipterigóide, que conecta as porções ventral e dorsal do crânio ancorado no menisco pterigóide (Kamal, 1972). A cartilagem de Meckel é uma das primeiras estruturas a aparecer no desenvolvimento; os dois ramos se fundem anteriormente na sínfise mandibular.

O aparelho columelar deriva da porção superior do arco hióideo. É composto pela columela, que se ossifica durante o desenvolvimento e é representada por uma haste projetada lateralmente e por uma base que fica ancorada na fenestra ovalis, e pela extracolumela, uma extensão da columela que permanece cartilaginosa (Baird, 1970), representada por uma pequena cartilagem com quatro processos, conectados ao processo paroccipital e à superfície interna do quadrado (Romer, 1956).

O aparelho hióide dos répteis deriva, evolutivamente, do esqueleto branquial dos arcos viscerais dos peixes. Está localizado na região ventral da boca e da faringe e oferece sustentação à musculatura da região (língua, garganta e da porção anterior da traquéia). É composto por um corpo hióide, um processo lingual medial que se estende anteriormente e três pares de cornos (projeções) saindo do corpo hióide e terminando em extremidades livres ou ligando-se a estruturas cranianas. Um par de cornos hióides direciona-se anteriormente e, da porção mediana destes, sai um epihial direcionado posteriormente; outros dois pares de ceratobranquiais saem do corpo hióideo direcionados posteriormente, sendo o primeiro par sempre mais desenvolvido. Epibranquiais distais podem estar unidos ao ceratobranquial ou podem estar livres.

Desenvolvimento do dermatocrânio: a maioria dos ossos dérmicos se forma tardia- 
mente em relação ao condrocrânio e o desenvolvimento completo só termina após o nascimento. O pterigóide é sempre o primeiro elemento dérmico a se desenvolver (Rieppel-1992a), e é logo seguido pelo suprangular, na mandíbula. O restante dos ossos dérmicos aparece relativamente ao mesmo tempo, mas pode haver variação entre as espécies. Geralmente, os últimos ossos a se desenvolverem são o nasal, o ectopterigóide e o lacrimal.

A pré-maxila única forma a ponta do focinho e estende-se posteriormente num processo nasal de tamanho e forma variando entre as espécies; um par de nasais ficam localizados lateralmente ao processo dorsal da pré-maxila. As septomaxilas pareadas têm forma de domo e envolvem e protegem o órgão de Jacobson; estão localizadas anteriormente, dentro das cápsulas óticas, entre o processo nasal da pré-maxila e o vômer, no palato.

No teto dorsal, um par de frontais e um par de parietais desenvolvem-se, inicialmente, nas margens laterais do crânio, como barras finas e alongadas, e expandem-se, posteriormente, para a região mediana dorsal, até se fundirem (em algumas espécies a fusão não ocorre e estes elementos permanecem pareados), fechando o teto dorsal (o fechamento só ocorre após o nascimento). A margem anterior do frontal pode ou não encontrar o processo nasal da pré-maxila medialmente e contata os nasais lateralmente (ou anteriormente, caso não contate a pré-maxila) e a margem posterior contata o parietal através de uma articulação que pode ter graus de complexidade diferentes entre as espécies. Em algumas espécies, um processo descendente de tamanho variado pode ser observado na região mediana lateral do parietal, à frente do epipterigóide, formando uma parede lateral que confere um grau de proteção maior ao crânio. Posteriormente, o parietal contata o supratemporal e o supraoccipital.

Dentre os elementos circumorbitais, estão presentes: lacrimais pareados anteriores às órbitas) muitas vezes associados aos pré-frontais, também pareados e com forma ligeiramente triangular, delineando a margem anterior das órbitas e contatando dorsalmente o frontal e ventralmente o palatino; maxilas normalmente bem desenvolvidas, com um processo facial cobrindo a lateral anterior à órbita e uma placa palatal participando da formação da região anterior e lateral do palato; jugais pareados delineando as margens ventral e posterior da órbita; e pós-frontais e pós-orbitais também pareados formando a margem posterior e dorsal da órbita.

Maxila e pré-maxila podem estar articuladas uma com a outra ou podem não estar em contato. O processo facial da maxila contata o nasal anteriormente e o pré-frontal posteriormente, e o processo orbital da maxila apoia o processo anterior do jugal. O jugal articula-se medialmente com o ectopterigóide e seu processo temporal dorsal contata o pós-orbital. Em alguns grupos, pós-frontal e pós-orbital podem estar fundidos numa estrutura única ou um ou outro podem estar ausentes. O pós-orbital se estende em um longo processo posterior e contata o processo anterior 
do esquamosal para formar o arco temporal superior. Esquamosal e supratemporal são os elementos dérmicos mais posteriores, localizados acima do quadrado.

Na região do palato (região ventral) são encontrados outros quatro elementos pareados, os vômeres, palatinos, ectopterigóides e pterigóides. Os vômeres são alongados e localizam-se na região anterior, ventralmente às cápsulas nasais. Os palatinos e os pterigóides são amplos e flanqueiam a trabécula. A superfície ventral do palatino é côncava e apresenta dois processos anteriores, um contatando a extremidade posterior do vômer e outro mais amplo que contata a placa palatal da maxila. O pterigóide apresenta, anteriormente, um processo palatino medial que se sobrepõe ao palatino, um processo transverso lateral que se articula com o ectopterigóide e um longo processo quadrado posterior que contata o quadrado; na superfície dorsal mediana a fossa columela apoia o epipterigóide. Os ectopterigóides são geralmente pequenos e localizados lateralmente.

Desenvolvimento da mandíbula: a mandíbula é formada por elementos dérmicos e endocondrais. O primeiro elemento que se forma, junto com as primeiras estruturas do condrocrânio, é a cartilagem de Meckel, que percorre toda a extensão da mandíbula.

O suprangular é o primeiro osso da mandíbula a aparecer. Os demais, dentário, esplenial, angular, coronóide e pré-articular, formam-se em fases mais tardias e desenvolvem-se aroximadamente ao mesmo tempo que a maioria dos ossos dérmicos do crânio.

O dentário é o elemento anterior da mandíbula e abriga a fileira marginal de dentes. Ocupa uma área considerável das superfícies labial e medial da mandíbula, estendendo-se, medialmente, por baixo do coronóide e contatando a margem anterior do esplenial e do pré-articular e o angular postero-ventralmente; na superfície labial, contata o suprangular postero-dorsalmente. A sínfise mandibular é formada pela união dos dentários através de uma sutura com interdigitações; a fusão completa pode ocorrer, mas também pode ocorrer um afrouxamento da sínfise para uma simples conexão por um ligamento (como nas cobras e alguns lagartos).

O esplenial estende-se postero-ventralmente e geralmente contata o coronóide e a margem anterior do pré-articular; está frequentemente ausente em muitos Squamata. O angular fica em posição ventro-medial, posterior ao esplenial, ventral e posterior ao dentário e ventral ao suprangular.

O suprangular forma a região superior e posterior da superfície labial da mandíbula, sobrepondo-se à margem externa posterior do articular; geralmente funde-se a este último e, em alguns répteis, cobre parte da superfície do articular. O coronóide fica localizado posterior e dorsalmente ao dentário. O pré-articular é o maior elemento da superfície medial da mandíbula; posteriormente, geralmente se funde à superfície interna do articular. 
Na extremidade posterior da cartilagem de Meckel, no local da articulação com o quadrado, ossifica-se o articular, o único osso endocondral da mandíbula; a articulação da mandíbula com o crânio ocorre na fossa glenóide, na superfície dorsal do elemento. É frequente o desenvolvimento de um processo retroarticular posterior ao articular, ao qual se liga o músculo depressor da mandíbula; o articular pode formar o corpo deste processo, mas outros elementos como o suprangular, angular e pré-articular podem cobrir parte ou toda a superfície deste processo. Na maioria dos répteis o articular está fusionado ao pré-articular e há uma grande tendência de fusão do suprangular com estes dois.

\section{Esqueleto axial}

Desenvolvimento dos elementos vertebrais: a notocorda, que sustenta o eixo do corpo do embrião nos estágios iniciais, é funcionalmente substituída por uma série de vértebras, que se formam ao redor desta e do tubo nervoso. A série vertebral pode ser dividida nas regiões pré-sacral (tronco), sacral (associada à pelvis) e caudal. Cada vértebra é composta por um centro cilíndrico (acima do qual passa o cordão nervoso), um arco neural que cresce para formar dorsalmente o espinho neural e, em muitos casos, um intercentro localizado ventralmente entre cada centro vertebral. Na região caudal, uma série de arcos hemais (ou chevrons) em forma de "V" podem se estender para baixo a partir do intercentro.

As vértebras se desenvolvem a partir das células do esclerótomo da série de somitos; estas células migram para perto da notocorda, englobando-a e ao tubo nervoso. O número de vértebras formadas corresponde ao número de somitos, porém um par de somitos não dá origem a uma única vértebra. O tecido mesenquimal de cada par de somitos é dividido em regiões cranial e caudal, sendo que a porção caudal de um somito se une à porção cranial do somito subsequente; cada vértebra se forma, então, a partir da união das duas metades de somitos e acabam ficando, consequentemente, intercaladas aos feixes da musculatura axial originada de cada somito.

Existe grande variação no que diz respeito à morfologia das vértebras, seja entre os grupos de répteis ou entre as vértebras de um único animal, podendo ocorrer grandes diferenças regionais. A seguir apresenta-se uma descrição geral das estruturas vertebrais básicas que podem compor cada vértebra.

O intercentro localiza-se entre as margens ventrais de centros vertebrais. Em muitos grupos atuais, o intercentro não está mais presente no tronco, sendo encontrado, como estruturas livres, apenas em gekkos e Sphenodon. Na região cervical, no entanto, o intercentro ainda persiste (livre ou fusionado a outros elementos) pelo menos nas duas primeiras vértebras em todos os répteis. Também são frequentemente encontrados na região caudal associados aos chevrons (ou 
arcos hemais) que, por sua vez, são universalmente retidos; nesta região os chevrons geralmente são em forma de "Y", com os braços ancorados no intercentro.

O centro vertebral é a porção mais importante para o suporte do peso corporal. Tem a forma cilíndrica e sua extremidade posterior geralmente tem um diâmetro maior e é mais espessa para articulação com a margem do centro vertebral subsequente. A superfície dorsal forma o assoalho do canal neural que engloba o tubo nervoso. A extremidade proximal da costela pode se ancorar no centro vertebral, ou se articular a um proceso que se projeta do corpo do centro, chamado parapófise. Quando presente, a parapófise localiza-se na parte anterior da coluna, na superfície lateral e inferior da porção anterior do centro; nas regiões mais posteriores, a tendência é de que a parapófise mova-se progressivamente para a superfície lateral superior e mais para perto da extremidade posterior do centro, aproximando-se da base do arco neural.

O arco neural é a porção dorsal da vértebra, cuja principal função é a de proteção da medula espinhal, envolvendo-a dorsal e lateralmente. Durante o desenvolvimento, os arcos surgem como estruturas pareadas, que crescem em direção à linha mediana dorsal até fundirem-se acima da medula para formar o arco. Acima do ponto de união, podem se erguer em um espinho neural mediano, que divide a musculatura epaxial do tronco e oferece superfície de inserção de músculos e tendões; conexões de ligamentos entre espinhas neurais sucessivas fortalecem mais ainda a coluna. Geralmente, os espinhos são maiores nos animais de maior porte e, normalmente, são mais alongadas nas vértebras anteriores. Os tecidos cartilaginosos do arco neural e do centro vertebral têm ossificação independente, mas ambos são fundidos nos adultos. De cada lado do arco surgem, geralmente, processos laterais (os processos tranversos) proeminentes, aos quais a costela se ancora distalmente.

Os arcos neurais sucessivos articulam-se entre si por processos chamados zigapófises; as zigapófises anteriores (pós-zigapófises) têm a superfície articular oval e voltada para cima e as posteriores (pré-zigapófises) têm a superfície articular ventral também oval e voltada para baixo. Articulações adicionais entre os arcos neurais podem estar presentes: geralmente répteis de corpos alongados e cobras, que se movem de maneira sinuosa, possuem processos acima das zigapófises, no ápice do arco neural, chamados zigósfeno (processo anterior) e zigântro (processo posterior); tais articulações fortalecem a coluna, mas restringem movimentos verticais.

Desenvolvimento das costelas: as costelas surgem do mesênquima localizado entre os "pacotes" (segmentos) sucessivos de músculos axiais. São estruturas endocondrais e a ossificação ocorre em todos os répteis, mas, em alguns casos, podem estar presentes elementos distais às costelas e articulações entre estas partes, que podem permanecer cartilaginosas. A natureza cartilaginosa das porções distais das costelas e as articulações móveis representam uma condição 
bastante importante de flexibilização dos movimentos respiratórios do animal.

Distais às costelas do tronco podem estar presentes prolongamentos, cujo nome varia de acordo com a conexão que faz com elementos da cintura escapular. Costelas esternais são as que se ligam ao esterno, as xifisternais se ligam ao xifisterno e as abdominais (aqui chamadas "costelas inscritas" - inscriptional ribs - segundo revisão da nomenclatura por Etheridge, 1965, por estarem associadas à musculatura ventral do abdômen) formam a série de placas pós-xifisternais (o conjunto destas placas é comumente chamado de parasterno, ou parasternália, mas aqui será chamado de pós-xifisterno) .

As costelas são geralmente alongadas, mas, em direção à região posterior do tronco, ficam progressivamente menores, podendo nem chegar a se desenvolver próximo à região sacral. $\mathrm{Na}$ região sacral não são observadas costelas, mas sim processos transversos fundidos numa estrutura robusta que se articula fortemente à cintura pélvica. As caudais, por sua vez, são estruturas bastante simples e mais frequentemente presentes nas vértebras mais proximais.

\section{Cinturas}

Nos diferentes grupos de Squamata, podem ser observados diversos graus de desenvolvimento das cinturas, relacionados ao tipo de locomoção e ao grau de desenvolvimento dos membros. Em formas que apresentam locomoção serpentiforme e que, portanto, possuem membros reduzidos, as cinturas associadas aos mesmos são geralmente reduzidas.

A cintura escapular é composta por elementos de origem dérmica e endocondral. Clavícula e interclavícula são os únicos elementos dérmicos; a clavícula é um dos primeiros elementos da cintura peitoral a ser formado no desenvolvimento e a interclavícula aparece em estágios mais tardios.

Os demais elementos, supraescápula, escápulo-coracóide, esterno, xifisterno e pós-xifisterno, são de formação endocondral. A supraescápula e a porção escapular do escápulo-coracóide surgem como uma única placa cartilaginosa, distinta da cartilagem da porção coracóidea do escápulo-coracóide. A ossificação se dá a partir de centros de ossificação distintos nesta placa; as porções escapular e coracóidea eventualmente se fundem e ossificam-se completamente (com exceção do epicoracóide, que forma a margem medial do escápulo-coracóide, contatando o esterno, e é formado por cartilagem calcificada), e a supraescápula não chega a se ossificar, sendo representada por cartilagem calcificada - assim como esterno, xifisterno e pós-xifisterno. 
O esterno é representado por uma placa ampla, localizada na região mediana ventral. Suas margens anteriores contatam os epicoracóides e, lateralmente, articula-se com as costelas esternais. Desenvolve-se, inicialmente, como duas placas cartilaginosas que se fundem ao longo do desenvolvimento embrionário. Normalmente, três pares de costelas esternais se ancoram ao esterno (mais raramente dois ou quatro pares).

O xifisterno localiza-se posterior ao esterno e, muitas vezes, funde-se a ele; um número variável de costelas xifisternais podem se ancorar ao xifisterno. Mais posteriormente, pode se desenvolver uma série de placas cartilaginosas a partir da fusão medial das extremidades dos pares de costelas inscritas em uma série de placas (chevrons) em forma de "X", que tem forte conexão com a musculatura e derme do ventre.

A cintura pélvica é formada apenas por elementos endocondrais, com três centros de ossificação correspondendo a cada um dos elementos (íleo, púbis e ísquio). Os três elementos unem-se no acetábulo, o local de articulação do fêmur com a cintura, enquanto púbis e ísquio unem-se na linha mediana através de sínfises cartilaginosas. No adulto as cartilagens desta região mediana persistem como o epipúbis (anterior), uma barra pró-isquiática correndo entre a sínfise dos ísquios e um hipoísquio projetado posteriormente. O íleo se articula (na sua superfície ventral) com a região sacral e as duas placas púbio-isquiádicas se ligam numa sínfise mediana ventral.

\section{Membros}

O desenvolvimento dos membros se dá no sentido próximo-distal, com estruturas mais proximais aparecendo mais cedo no desenvolvimento. Os membros são divididos em três segmentos: o mais proximal (estilopódio), composto pelo úmero no membro anterior e fêmur no membro posterior, o intermediário (zeugopódio), composto pelos pares rádio/ulna no membro anterior e tíbia/fíbula no membro posterior, e o mais distal (autopódio), composto pela série de carpais, metacarpais e falanges no membro anterior e tarsais, metatarsais e falanges no membro posterior.

Há uma enorme variação nos elementos que compõem os membros entre os diferentes grupos. A redução de elementos é um evento bastante frequente em Squamata e está, geralmente, associada à fusão e/ou perda dos mesmos (hipótese que é suportada principalmente por evidências embriológicas) e, em lagartos com padrão corpóreo serpentiforme e nas cobras, pode ocorrer a perda ou a total ausência dos membros.

No estilopódio do membro anterior, o úmero é alongado, com a extremidade proximal oval levemente curvada dorsal e posteriormente em relação ao eixo do osso, e com a extremidade distal com áreas de articulação para a ulna (côndilo ulnar) e para o rádio (côndilo radial). 
No zeugopódio, o rádio é expandido nas duas extremidades; a superfície articular proximal oca e oval encaixa-se no côndilo radial do úmero, e a superfície distal, chata e oval, articula-se com o carpo radial. A ulna apresenta uma superfície articular curva, encaixando-se no côndilo ulnar do úmero, e a extremidade distal é achatada dorso-ventralmente e mais estreita, articulando-se com os carpos intermédio e ulnar e com o pisciforme.

A série de carpais é bastante variada, já que diversos elementos podem estar ausentes de acordo com o grau de especialização ou de redução do membro. A série é basicamente composta por elementos proximais, centrais e distais. Entre os elementos proximais estão presentes o radial, localizado abaixo do rádio e suportando a maior parte do peso transmitido por esse osso, o ulnar, localizado abaixo da ulna, o intermédio, encaixado entre rádio e ulna e suportando parcialmente estes dois elementos, e o pisciforme, localizado ventralmente entre a ulna e o ulnar. Entre os carpais e os carpais distais, encontra-se um grande central medial (ou apenas central) interposto entre o radial e o ulnar, logo abaixo do intermédio, e um central lateral achatado próximo-distalmente entre o radial e os 3 elementos internos da série de carpais distais. Distalmente a estes elementos está a série de carpais distais, formando uma fileira acima das cabeças dos metacarpais. No padrão primitivo estão presentes 5 carpais distais, dos quais o $4^{\circ}$ é o maior e o $5^{\circ}$ o menor; os 2 primeiros localizam-se abaixo do central lateral, o $3^{\circ}$ fica abaixo do central medial (mas geralmente contata o central lateral), o $4^{\circ}$ contata apenas o ulnar e o medial central e o $5^{\mathrm{o}}$ só tem contato com o ulnar.

No membro posterior, o fêmur é um elemento bastante longo, cilíndrico, ligeiramente expandido na parte proximal para se articular ao acetábulo e curvado na parte distal.

A tíbia é o elemento mais robusto do zeugopódio. Articula-se com os dois côndilos do fêmur por um par de superfícies amplas e, na sua parte distal, uma superfície também ampla articula-se com o astragalo-calcâneo. A fíbula é mais delgada, expandida nas duas extremidades, e bastante côncava; a superfície articular proximal encaixa-se numa área correspondente do côndilo lateral da tíbia. Praticamente todo o peso do corpo é suportado pela tíbia, a fíbula tem papel mais importante para fornecer área de inserção e ligação muscular.

A série de tarsais é composta por três elementos, o astragalo-calcâneo e os tarsais distais 3 e 4. O astragalo-calcâneo é o maior dos três e levemente côncavo e achatado dorso-ventralmente; suporta a tíbia e a fíbula e articula com os tarsais distais 3 e 4 ventralmente. Os metatarsais do primeiro e quinto dígitos articulam-se com as extremidades laterais do astragalo-calcâneo.

Os autopódios dos membros anterior e posterior são formados por uma série de dígitos, cada um composto por um elemento proximal mais alongado (metacarpal/metatarsal) e uma série de falanges distais a estes elementos, todos morfologicamente semelhantes; a última falange 
do dedo, que apresenta unha ou garra, é chamada falange ungual.

Os metacarpais/metatarsais apresentam aumento de tamanho progressivo do $1^{\circ}$ ao $4^{\circ}$ elemento, e o $5^{\circ}$ é menor e mais fino; a porção proximal destes elementos é mais expandida para articulação com os carpais/tarsais distais. As falanges são geralmente menores que os metacarpais/metatarsais e há uma progressiva diminuição de tamanho entre as falanges à medida que se aproximam da região mais distal da mão/pé.

A fórmula falângea é utilizada para expressar o número de falanges encontradas em cada dígito. É escrita sempre com 5 números que representam cada um dos dígitos, no sentido antero-posterior, dentro de um padrão pentadáctilo. Desta forma, o primeiro número representa o número de falanges presentes no $1^{\circ}$ dígito, e assim por diante até o $5^{\circ}$ dígito. Um réptil pentadáctilo típico apresenta a fórmula falângea da mão como 2-3-4-5-3, e dos pés 2-3-4-5-4.

\subsection{REGULAÇÃO GÊNICA DO DESENVOLVIMENTO}

O desenvolvimento embrionário é arquitetado a partir de complexos padrões de expressão de genes oraganizados espaço-temporalmente (Giudice, 2001), que regem a construção do organismo, e que são extremamente conservados entre os grupos (Thomson, 1988; Hall, 1992; Kimble e Smith, 1996; Richardson et al., 1999; Carroll et al., 2000). Variações nestes padrões são, na maioria das vezes, os mecanismos responsáveis pela diversidade fenotípica (Gould, 1977; Raff, 1996; Dover, 2000; Wagner, 2001).

Estudos sobre as variações nos padrões de expressão de genes ao longo do desenvolvimento auxiliam na compreensão dos padrões evolutivos observados nas diversas formas de vida existentes. Alterações nos padrões de expressão gênica podem abranger desde a inativação de cascatas genéticas até modificações nos tempos e taxas de expressão de genes, sejam estes genes reguladores ou estruturais; quando tais alterações ocorrem durante a construção do organismo, representam a principal fonte de introdução de modificação evolutiva.

Entretanto, devemos considerar o problema de quão representativas são as espécies utilizadas em estudos sobre a evolução do desenvolvimento. Grande parte dos estudos utiliza espécies "modelo", chamadas como tal devido à facilidade de obtenção, trabalho e manipulação dos ovos e dos embriões. Entre os vertebrados, podemos citar como exemplos os extensos trabalhos realizados com peixe paulistinha (ou zebrafish; Danio rerio), sapo africano (Xenopus laevis), galinha (Gallus domesticus) e camundongos (Mus musculus), dos quais deriva uma vasta e importante literatura a respeito dos mecanismos moleculares que regem o desenvolvimento embrionário. 
Além disso, são realizados diversos estudos experimentais que modificam determinadas etapas do desenvolvimento para analisar como o sistema em questão se comporta em cada caso. Um dos maiores exemplos destas manipulações em vertebrados são os experimentos que envolvem o desenvolvimento dos membros, nos quais são realizadas interferências artificiais nos embriões para observar o resultado e criar, então, hipóteses mais abrangentes que possam ser extrapoladas para outros sistemas biológicos.

Apesar destes dados, produzidos a partir de um número bastante pequeno de espécies, serem de extrema importância ao conhecimento da biologia do desenvolvimento dos animais, podem não ser representativos da diversidade de formas existentes. Muitas vezes, pesquisadores sentem-se tentados a realizar inferências a respeito dos processos que podem reger o desenvolvimento de espécies distantemente relacionadas ao modelo de estudo e, apesar de inferências deste tipo serem importantes, uma vez que abrem perspectivas de pesquisas, não necessariamente refletem os processos que podem de fato estar organizando a construção de indivíduos de outro grupo. Assim, muitos dos mecanismos de desenvolvimento e redução de estruturas são conhecidos apenas por meio de mutações e deleções obtidas em linhagens de laboratório e, portanto, não provêem um contexto adequado para investigações sobre os processos do desenvolvimento responsáveis pela grande diversidade morfológica observada nos mais diversos grupos (Shapiro et al., 2003). E é a partir deste problema que cresce cada vez mais a necessidade de se buscar alternativas a estes "animais modelo" e tentar, então, obter resultados mais próximos da realidade.

Neste sentido, a investigação comparativa sobre os padrões de expressão dos genes dentro de um grupo de espécies proximamente relacionadas e que apresentam variações de planos corpóreos, permite que sejam feitas inferências sobre os processos de desenvolvimento que podem ter sido responsáveis pela evolução do grupo.

O grupo Squamata é um ótimo modelo para estudos com foco nas grandes modificações de planos corpóreos (Brandley et al., 2009). Aproximadamente 8200 espécies de lagartos, cobras e anfisbenas compõem o grupo (Uetz, 2007) e, apesar da maioria destas espécies ser representada por lagartos típicos com membros pentadáctilos (Pough et al., 2004), ocorreram inúmeras transições destes planos corpóreos lacertiformes para planos serpentiformes em diversas famílias, com o alongamento do corpo e redução dos membros, além de outras características associadas (Camp, 1923; Gans, 1975; Greer, 1991; Caldewell, 2003; Wiens et al., 2006). Em algumas das famílias (como exemplo Anguidae, Gymnophthalmidae e Scincidae), a modificação para a morfologia serpentiforme teve origem independente e convergente em várias linhagens ou até no mesmo gênero (Cogger, 1992; Wiens et al., 2006; Uetz, 2007); além disso, podem ser encontradas formas com morfologias intermediárias, favorecendo estudos comparativos (Lande, 1978; Shapiro et al., 
2003; Wiens et al., 2006). A evolução de planos corpóreos serpentiformes em espécies proximamente relacionadas é um modelo promissor para estudos sobre as modificações dos padrões de desenvolvimento ao longo da história evolutiva das mesmas.

Os lagartos da tribo Gymnophthalmini são exemplo de um grupo para o qual a análise comparada do desenvolvimento embrionário pode elucidar os possíveis mecanismos envolvidos nos processos de alongamento do corpo e redução apendicular, levando à rápida transformação de plano corpóreo. As relações filogenéticas bem estabelecidas (Rodrigues, 1995 e Pellegrino et al., 2001) e a diferenciação relativamente recente do plano corpóreo serpentiforme de Calyptommatus e Nothobachia (como observada no trabalho de Benozzati e Rodrigues, 2003), representando alto grau de adaptação à fossorialidade, torna-os candidatos ideais para uma investigação comparativa dos mecanismos de desenvolvimento (morfológicos e epigenéticos) responsáveis por sua origem evolutiva.

Deste modo, podem ser considerados ótimos modelos para estudos de desenvolvimento que envolvam a identificação dos padrões de expressão gênica responsáveis pela origem destas grandes modificações em um tempo relativamente tão curto. Os mecanismos envolvidos nos processos de alongamento do corpo e redução apendicular podem ser analisados a partir de estudos comparativos sobre os padrões de expressão dos genes reguladores da segmentação embrionária, dos genes homeóticos e de outros envolvidos com a determinação e especificação dos limites axiais, e de genes coordenando o desenvolvimento e redução dos membros e das cinturas em cada uma das espécies estudadas.

\subsubsection{Desenvolvimento e padronização dos membros}

O desenvolvimento de membros dos tetrapodes é um dos principais e mais bem conhecidos modelos no campo da Biologia do Desenvolvimento (Johnson e Tabin, 1997; Gilbert, 2006). Os membros são considerados como módulos praticamente autônomos que seguem uma sequência de desenvolvimento muito bem estruturada por cascatas de expressão de genes organizadas espacial e temporalmente, que coordenam a construção de uma estrutura completa e funcional. Estudos experimentais sobre o desenvolvimento dos membros mostraram que as regras básicas de construção dos mesmos são basicamente as mesmas para o os tetrápodes (Shubin e Alberch, 1986), com moléculas de sinalização que desempenham papel fundamental na determinação dos três eixos do membro: fator de crescimento do fibroblasto (FGF), regulando o eixo próximo-distal; sonic hedgehog (Shh), regulando o eixo antero-posterior e Wnt7a, regulando parte do eixo dorso-ventral (Gilbert, 2006).

Porém, a representatividade de espécies deste grupo em estudos de desenvolvimento ainda é muito baixa, restringindo-se às tais chamadas espécies-modelo. É provável que as regras básicas 
realmente não sejam diferentes entre os animais, mas, diante da diversidade de planos corpóreos existentes, há grandes chances que existam variações atuando sobre estas regras, alterando assim o processo de construção (como mostram Raynaud, 1990; Christen e Slack, 1998; Richardson et al., 1998; Cohn e Tickle, 1999; Hanken et al., 2001; Shapiro et al., 2003 e Thewissen et al., 2006). Além disso, os mecanismos de redução dos membros são conhecidos apenas por meio de mutações e deleções obtidas em linhagens de laboratório, não provendo, portanto, uma base sólida para investigações sobre os mecanismos de desenvolvimento responsáveis pela grande diversidade morfológica observada nos mais diversos grupos (Shapiro et al., 2003).

O processo de desenvolvimento dos membros pode ser definido e dividido em quatro fases principais: a especificação do local onde o membro irá se desenvolver (campo do membro), o aparecimento inicial dos brotos dos membros, o crescimento e padronização dos três eixos dos membros e a diferenciação de tecidos de sustentação, com o modelamento final dos membros.

\section{Especificação do campo do membro}

A posição na qual os membros irão se desenvolver é sempre constante em relação ao nível de expressão dos genes Hox ao longo do eixo antero-posterior do corpo (Gilbert, 2006); o membro anterior, por exemplo, sempre se desenvolve no limite de expressão mais anterior do Hoxc-6 (Burke et al., 1995). Ainda, o ácido retinóico se apresenta em um gradiente ao longo do eixo antero-posterior que pode ativar a expressão de certos Hox em determinadas células, especificando-as a serem incluídas no campo do membro (Bryant e Gardiner, 1992).

\section{Aparecimento dos brotos dos membros}

O aparecimento dos brotos dos membros começa com a proliferação das células mesenquimais da placa lateral e dos somitos; o sinal inicial para essa proliferação é a secreção do fator de crescimento $F G F 10$, expresso pelas células da placa lateral, e que é capaz de iniciar as interações entre as células mesenquimais e a ectoderme (Gilbert, 2006).

\section{Crescimento e padronização dos eixos dos membros}

O membro é um sistema com três eixos (próximo-distal, antero-posterior e dorso-ventral) que são arquitetados durante o desenvolvimento.

O desenvolvimento no eixo próximo-distal é coordenado pela crista apical ectodérmica (AER, figura 1.4), um espessamento das células ectodérmicas da margem distal do broto do membro, entre as faces dorsal e ventral, que representa um dos principais centros de sinalização para a coordenação e padronização do membro em desenvolvimento (figura 1.5; Saunders, 1948; Laufer et al., 1997; Sun et al., 2002; Harfe et al., 2004; Gilbert, 2006; entre outros); sua atividade é 
muito bem estabelecida para espécies como Xenopus laevis (sapo africano), Gallus domesticus (galinha) e Mus musculus (camundongos). Para tais animais, a presença da AER é necessária para o correto desenvolvimento dos membros; a remoção experimental gera membros truncados (Saunders, 1948; Summerbell, 1974; Rowe e Fallon, 1982). A secreção de FGF1O pelas células mesenquimais induz a formação desta estrutura que, por sua vez, responde com a secreção de FGF8, mantendo a proliferação e o estágio não diferenciado das células do mesênquima (Johnson e Tabin, 1997; Gilbert, 2006), além de manter a expressão de moléculas que coordenam os eixos antero-posterior e dorso-ventral e interagir com as mesmas, a ponto de organizar a diferenciação das células do membro (Harfe et al., 2004; Gilbert, 2006). Além disso, outros FGFs são expressos pela AER, em diferentes tempos do desenvolvimento, como o FGF2, FGF4 e FGF9, por exemplo.

Como a crista apical é um importante centro de sinalização, qualquer falha na sua estrutura leva à falhas no desenvolvimento dos membros: remoções experimentais desta região resultam na formação de membros truncados, sendo que o grau de truncamento depende da fase de desenvolvimento do membro em que a AER foi retirada (Saunders, 1948; Rowe e Fallon, 1982); remoções realizadas em estágios iniciais levam a truncamentos mais proximais, enquanto remoções em estágios mais tardios levam a truncamentos mais distais. A remoção da AER e a subsequente adição de FGF8 ectópico levam ao desenvolvimento normal do membro (Vogel et al., 1996), sugerindo que esta molécula seja, portanto, essencial para a manutenção das funções da AER e para a formação completa dos membros (Lewandoski et al., 2000).
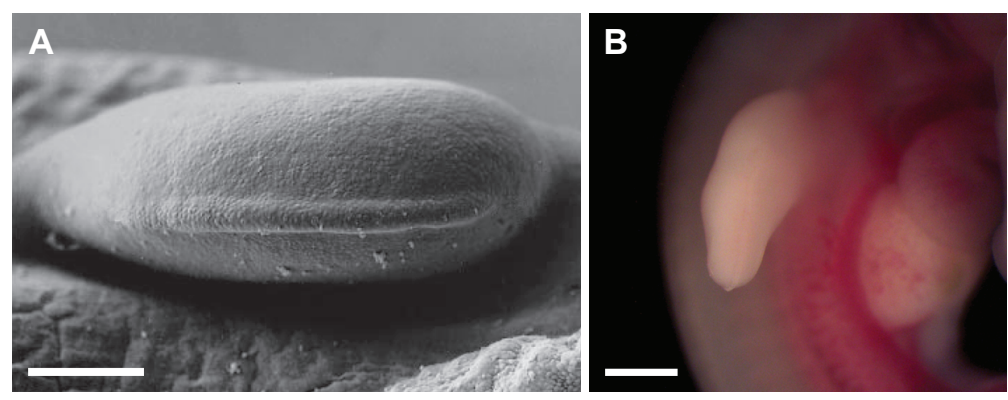

Figura 1.4. Foto de microscopia eletrônica mostrando a crista apical (seta) do broto de membro de um embrião de camundongo (adaptado de http://www.med.unc.edu/embryo images). B. Membro anterior de um embrião de Cnemidophorus sp., com a crista apical distal, vista sob estereomicroscópio.

O desenvolvimento no eixo antero-posterior é coordenado pela molécula Sonic Hedgehog (shh), expressa pelas células da Zona de Atividade Polarizadora (ZPA; Saunders e Gasseling, 1968; Riddle et al., 1993), um pequeno agregado mesodérmico na região posterior do membro. As células desta região são induzidas à secretarem o shh pelo estímulo de $F G F 8$ vindo da AER (figura 1.5). Acredita-se que duas moléculas sejam responsáveis por restringir a resposta ao $F G F 8$ apenas à região da ZPA, dando competência apenas às células da ZPA a secretarem o shh: o gene Hoxb-8, 
expresso na região posterior do membro (Charité et al., 1994), e o $d H A N D$, expresso inicialmente em todo o broto do membro e restringindo-se, em estágios posteriores, à mesoderme da região posterior, sendo condição necessária para a expressão de shh (Charité et al., 200o; Fernandez-Teran et al., 2000).

A atividade do shh na ZPA é detectada desde os estágios iniciais do desenvolvimento do membro e permanece até que os dígitos comecem a ser formados (Tickle, 2006). Sugere-se, portanto, que a molécula confira valor posicional às células do broto em estágios iniciais e que a identidade dos dígitos seja especificada de maneira tempo/gradiente-dependente (Harfe et al., 2004; Gilbert, 2006; Towers e Tickel, 2009). Assim, em membros pentadáctilos normais, a diferença entre a especificação dos dígitos 4 e 5 é que as células mais posteriores do dígito 5 expressam shh por mais tempo e, portanto, estão expostas ao sinal (de maneira autócrina) por mais tempo que as células do dígito 4 . Na região do dígito 3 as células também expressam shh, porém por menor tempo, e ainda dependem da difusão dos sinais vindos da ZPA. O dígito 2 é totalmente dependente da difusão e o dígito 1 é especificado independentemente (Gilbert, 2006).

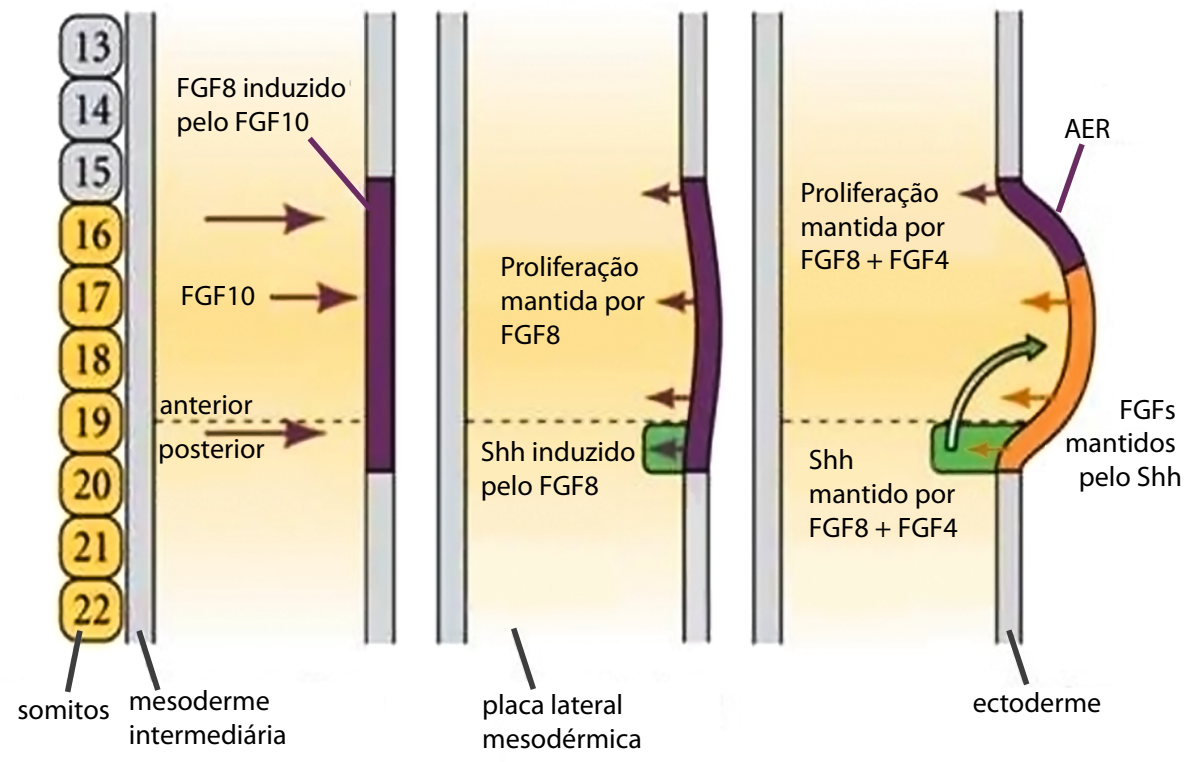

Figura 1.5. Representação esquemática da sinalização molecular que coordena o desenvolvimento dos eixos próximo-distal e antero-posterior e a interação entre ambos ao longo do tempo. Modificado de Gilbert (2006).

O desenvolvimento no eixo dorso-ventral é coordenado pela molécula Wnt7a, expressa apenas na ectoderme dorsal do broto do membro (Dealy et al., 1993; Parr et al., 1993; Gilbert, 2006); o Wnt7a induz a expressão de outra molécula $L m x 1$, essencial para a especificação de características dorsais às células, e mantém a expressão de shh e $F G F 4$ na região posterior da AER (Gilbert, 2006). 


\section{Diferenciação dos tecidos de sustentação}

A formação de cartilagem envolve os processos de condensação e diferenciação. Durante o período de condensação, o mesênquima pré-cartilaginoso é segregado em regiões condrogênicas e não condrogênicas e, em seguida, os agregados pré-condrogênicos entram no estágio de diferenciação (Chimal-Monroy et al., 2003). Os principais sinais regulatórios envolvidos na diferenciação das células do membro em tecido cartilaginoso são as moléculas Sox e BMPs (Chimal-Monroy et al., 2003; Akiyama et al., 2002).

\subsubsection{Redução de membros}

A evolução de planos corpóreos com membros reduzidos ou ausentes ocorreu diversas vezes na história evolutiva dos vertebrados e foi, geralmente, acompanhada pelo alongamento do corpo e pela perda da diferenciação regional do esqueleto axial (Carroll, 1988). Entre os tetrápodas, podemos observar tal tendência entre anfíbios (cecílias e salamandras; Romer, 1966; Alberch e Gale, 1985), répteis (lagartos serpentiformes, cobras e anfisbenas; Greer, 1987, 1991; Brandley et al., 2008), aves e mamíferos (cetáceos; Thewissen et al., 1997).

A redução dos membros ocorre, a grosso modo, em sentido contrário ao desenvolvimento dos mesmos (Cope, 1892; Stokely, 1947; Lande, 1978; Rieppel, 1992), com os elementos distais desaparecendo antes que os proximais. Geralmente os dígitos são perdidos na seguinte ordem: I $>$ V > II $>$ III > IV (Greer, 1987 e 1991; Rieppel, 1992); tal fato pode ser devido à adaptações locomotoras (como a hipótese de Greer, 1991, sobre o papel central dos dedos III e IV nas funções locomotoras do autopódio) ou à restrições do desenvolvimento (devido ao alto grau de conservação dos programas de desenvolvimento que podem limitar o espectro de morfologias potenciais; Shubin e Alberch, 1986), ou à ambas (Shapiro, 2002).

Há uma série de informações sobre a morfologia de squamatas adultos que apresentam membros reduzidos (Cope, 1892; Greer, 1987, 1990, 1991; entre vários outros), mas as origens embrionárias de tais morfologias ainda não receberam a devida atenção (Shapiro, 2002). Há uma rica literatura sobre o desenvolvimento do ponto de vista morfológico e molecular dos membros de poucas espécies de tetrápodes, como Xenopus laevis, Gallus domesticus e Mus musculus, no entanto, os mecanismos de desenvolvimento responsáveis pela redução dos membros ainda não são bem conhecidos (Shapiro et al., 2003).

Alguns estudos recentes envolvendo grupos diferentes e com histórias evolutivas específicas (Raynaud, 1990; Cohn e Tickle, 1999; Shapiro, 2002; Shapiro et al., 2003; Wiens e Slingluff, 2006) estão começando a desvendar alguns dos processos do desenvolvimento que podem ter sido responsáveis pelo desenvolvimento incompleto dos membros ou pela total ausência dos 
mesmos. A presença temporária da AER nos membros de Anguis fragilis e Stenella attenuata (Raynaud, 1990 e Thewissen et al., 2006, respectivamente) ou a ausência completa da mesma em pítons (Cohn e Tickle, 1999), e a redução no tempo de expressão de shh em espécies com número reduzido de dígitos (Shapiro et al., 2003) ou a total ausência de expressão de shh em S. attenuata e em píton, sendo que nesta última há também a ausência total de expressão de genes padronizadores dos eixos próximo-distal e dorso-ventral (Thewissen et al., 2006 e Cohn e Tickle, 1999, respectivamente), são exemplos de processos que levam à formação de membros reduzidos.

Tais trabalhos são importantes pois demonstram a existência de variações naturais nos planos de desenvolvimento dos membros e a necessidade da realização de estudos sobre a evolução dos mecanismos do desenvolvimento com grupos de espécies próximas que compartilham uma história evolutiva interessante. Desta forma, questões mais abrangentes relacionadas ao surgimento de novos planos corpóreos podem ser analisadas com mais detalhes e fundamentadas em informações mais confiáveis do ponto de vista filogenético.

\subsection{OBJETIVOS}

O objetivo deste trabalho é analisar aspectos da morfologia externa e do esqueleto, ao longo do desenvolvimento embrionário de cinco gêneros da tribo Gymnophthalmini, para identificar os mecanismos envolvidos nos processos de redução apendicular, alongamento do corpo e outras modificações osteológicas na história evolutiva do grupo.

O primeiro passo é o conhecimento dos processos morfogenéticos que acontecem durante a ontogenia do organismo; a ferramenta para estudos deste tipo é a elaboração de tabelas de desenvolvimento, nas quais o desenvolvimento do organismo é descrito e dividido em estágios que mostram as principais mudanças morfológicas ao longo do tempo. Com base nestas tabelas, podem ser realizadas comparações entre taxas e tempos de desenvolvimento de determinadas estruturas em espécies próximas; além disso, as tabelas fornecem a base essencial para a padronização de estudos experimentais.

As informações obtidas a partir das análises da morfologia externa e do desenvolvimento ósseo e cartilaginoso serão complementadas com informações sobre os padrões de expressão gênica relacionados ao desenvolvimento e redução dos membros e ao alongamento do corpo, fornecendo modelos sobre a biologia do desenvolvimento deste grupo em particular. Ao mesmo tempo, poderão ser inseridas num espectro muito mais amplo, possibilitando inferências sobre a evolução dos mecanismos de desenvolvimento e sobre as possíveis modificações que podem ter 
levado às mudanças macroevolutivas em direção ao surgimento de formas mais serpentiformes.

As metas são, portanto:

I. Descrever o desenvolvimento da morfologia externa dos embriões de Calyptommatus sinebrachiatus, Nothobachia ablephara, Vanzosaura rubricauda, Psilophthalmus paeminosus e Procellosaurinus tetradactylus e elaborar tabelas de desenvolvimento que estabeleçam fases ontogenéticas para caracterizar o desenvolvimento destas espécies.

II. Descrever detalhadamente a organização do esqueleto dos adultos de C. sinebrachiatus, N. ablephara, Scriptosaura catimbau, V. rubricauda, P. paeminosus e P. tetradactylus.

III. Descrever o desenvolvimento dos elementos de sustentação dos embriões de C. sinebrachiatus, N. ablephara, V. rubricauda, P. paeminosus e P. tetradactylus.

IV. Comparar a variação intragenérica da morfologia externa e interna dos embriões de modo a detectar padrões evolutivos ao longo do desenvolvimento.

V. Analisar o desenvolvimento e redução dos membros nas espécies da tribo Gymnophthalmini através de uma abordagem morfológica-molecular.

VI. Relacionar estes aspectos à evolução dos padrões corpóreos em Squamata. 


\section{CAPÍTULO 5 \\ CONCLUSÃO}

Complexos adaptativos distintos apresentados pelos Gymnophthalmini fossoriais mostram íntima relação entre a morfologia e o modo de vida. Muitas das características relacionadas à modificação do crânio para sua utilização na locomoção são frequentes em outros grupos de lagartos e envolvem modificações voltadas à proteção do encéfalo e órgãos do sentido através do fortalecimento de articulações, redução de espaços abertos e crescimento pronunciado de estruturas junto com a redução ou perda de outras.

Características relacionadas à modificações do corpo, cinturas e membros são ainda mais óbvias nas espécies adaptadas à vida fossorial. Como discutido por Gans (1975), o alongamento do corpo é considerado como a primeira resposta seletiva à ocupação de habitats mais protegidos, nos quais os animais tenham que se locomover em meio a fendas ou túneis formados por ambientes com folhiço e/ou pedras, ou solos arenosos. Os membros, nestes ambientes, aumentariam o diâmetro do corpo e dificultariam, por consequência, a locomoção; por este motivo, o desenvolvimento da locomoção através de ondulações e a redução/perda dos membros seriam favorecidas. Este complexo de respostas adaptativas é frequentemente (e independentemente) observado em espécies com hábito fossorial (Gans, 1975; Lee, 1998), e podem surgir em curtos períodos de tempo, como observado nos Gymnophthalmini (Benozatti e Rodrigues, 2003). Paralelamente, observa-se modificações extremamente semelhantes nos mamíferos com adaptações para a vida aquática, que também estão relacionadas ao alongamento do corpo e redução dos membros, características associadas à transição para a locomoção axial (Bejder e Hall, 2002).

Os mecanismos do desenvolvimento embrionário que conferem modificações evolutivas na morfologia são, geralmente, resultantes de diferenças nas expressões de genes reguladores, que podem ser decorrentes de variações temporais ou espaciais dos mecanismos "originais" (ou ancestrais) (Raff e Wray, 1999). A existência de tais variações implica na necessidade da dissociação entre os processos do desenvolvimento de forma a permitir o estabelecimento de novas trajetórias que levam à diferentes fenótipos. Apesar desta dissociação ser relativamente restrita devido à existência de interações que não podem ser modificadas (as "macrointerações"), as diferenças evolutivas surgem de flexibilizações de caminhos de desenvolvimento que atuam dentro destas interações maiores; modificações nesta esfera não levam à morfologias inviáveis do ponto de vista evolutivo.

A história evolutiva do grupo Gymnophthalmini é marcada por eventos heterocrônicos atuando nas modificações morfológicas associadas à fossorialidade, especialmente no alongamento 
do corpo e redução dos membros. As mudanças nas taxas e/ou tempos de expressão de genes reguladores da somitogênese e do desenvolvimento dos brotos dos membros foram essenciais para o surgimento de variações que foram fixadas nas linhagens fossoriais. Ainda, modificações semelhantes são encontradas em diversos outros grupos de vertebrados com padrão corpóreo similar, sugerindo a existência de um modelo de desenvolvimento básico que permite o surgimento de micro-variações em resposta à pressões adaptativas. Deste modo, pressões semelhantes resultariam em fenótipos semelhantes, mas que não se originariam, necessariamente, a partir das mesmas modificações moleculares, apesar de as evidências apresentadas aqui e na literatura mostrarem que, na maioria dos casos, estas modificações são, de fato, semelhantes.

O fato de a linhagem dos Gymnophthalmini ser recente (7-8 milhões de anos; Benozatti e Rodrigues, 2003) mostra que, apesar de os planos corpóreos entre as espécies serem diferentes, estas mudanças drásticas podem ocorrer em períodos de tempo relativamente curtos, já que uma pequena variação na expressão de um gene padronizador pode resultar em uma variação fenotípica marcante. No entanto, essas mudanças levam um certo tempo para se fixar evolutivamente e, como mostram Brandley et al. (2008), a transição de formas com membros completos e bem desenvolvidos para formas com membros totalmente ausentes nunca ocorreu em tempo menor que 16 milhões de anos (inclusive colocando a linhagem dos Gymnophthalmini na análise).

A incrível diversidade de formas de vida observada entre os répteis, que vão desde formas fossoriais, como as estudadas, à formas adaptadas à vida aquática ou arborícola, confere a este grupo uma importância enorme para o conhecimento dos mecanismos de desenvolvimento atuantes nas variações fenotípicas naturais. A inclusão cada vez maior destas espécies de répteis nas pesquisas sobre a evolução do desenvolvimento é fundamental para ampliar o conhecimento da diversificação ontogenética ao longo da evolução, incluindo eventos como a origem do grupo das serpentes a partir de lagartos fossoriais. 


\section{REFERÊNCIAS}

Ab'Saber NA. 1977. Os domínios morfoclimáticos da América do Sul. Primeira aproximação. Geomorfologia. 53: 1-23.

Alberch P, Gale E. 1985. A developmental analysis of an evolutionary trend: digital reduction in amphibians. Evolution. 39: 8-23.

Alberch P, Gould SJ, Oster GF, Wake DB. 1979. Size and shape in ontogeny and phylogeny. Paleobiology. 5(3): 296-317.

Akiyama H, Chaboissier M, Martin JF, Schedl A, Crombrugghe B. 2002. The transcription factor Sox9 has essential roles in successive steps of the chondrocyte differentiation pathway and is required for expression of Sox5 and Sox6. Genes and Development. 16:28132828 .

Andrews RM. 2004. Patterns of embryonic development. In:. Reptilian incubation. Environment, evolution and behaviour. Deeming DC, ed. Nottingham University Press, Nottingham, UK. p 75-102.

Andrews RM, Mathies T. 20oo. Natural history of reptilian development: constraints on the evolution of viviparity. BioScience. 50(3): 227-238.

Arthur W. 1984. Mechanisms of morphological evolution. John Wiley \& Sons, New York.

Arthur W. 2002. The emerging conceptual framework of evolutionary developmental biology. Nature. 415: 757-764.

Baird IL. 1970. The anatomy of the reptilian ear. In: Biology of the Reptilia. Gans C e Parsons TS, eds. Academic Press, London e New York. Vol2: 193-275.

de Beer GR. 1930. The early development of the chondrocranium of the lizard.

de Beer GR. 1937. The development of the vertebrate skull. Oxford: Clarendon Press. 554 p.

de Beer GR. 1951. Embryos and Ancestors. Oxford Clarendon Press. 159p.

Bejder L, Hall BK. 2002. Limbs in whales and limblessness in other vertebrates: mechanisms of evolutionary and developmental transformation and loss. Evolution \& Development. 4: $445-458$.

Bell CJ, Evans SE, Maisano JA. 2003. The skull of the gymnophthalmid lizard Neusticurus ecpleopus (Reptilia: Squamata). Zoological Journal of the Linnean Society. 139: 283-304.

Bellairs A. 1949a. The anterior braincase and interorbital septum of Sauropsida, with consideration on the origin of snakes. Journal of the Linnean Society (Zoology). 41: 482-512. 
Bellairs A. 1949b. Observation of the snout of Varanus, and a comparison with that of other lizards and snakes. Journal of Anatomy. 83: 116-146.

Bellairs A. 1950. Observations of the cranial anatomy of Aniella, and a comparison with that of other burrowing lizards. Proceedings of the Zoological Society of London. 119; 887-904.

Bellairs A. 1958. The early development of the interorbital septum and the fate of the anterior orbital cartilages in the birds. Journal of Embryology and Experimental Morphology. 6: 68-85.

Bellairs A. 1965. Cleft palate, microphthalmia and other malformations in embryos of lizards and snakes. Proceedings of the Zoological Society of London. 144: 239-251.

Bellairs A, Kamal AM. 1981. The chondrocranium and the development of the skull in recent reptiles. In: Biology of the Reptilia. Gans C e Parsons TS, eds. New York Academic Press. Vol.11, Morphology F: 1-263.

Benozzati ML, Rodrigues MT. 2003. Mitochondrial restriction-site characterization of a Brazilian group of eyelid-less gymnophthalmid lizards. Journal of Herpetology. 37(1): 161-68.

Billett F, Gans C, Maderson PFA. 1985. Why study reptilian development? In: Biology of the Reptilia. Gans C, Billett F, Maderson PFA, eds. Vol. 14, Development A. Wiley \& Sons, New York. p 1-39.

Blagden CS, Currie PD, Ingham PW, Hughes SM. 1997. Notochord induction of zebrafish slow muscle mediated by Sonic hedgehog. Genes and Development. 11: 2163-2175.

Bolker JA. 200o. Modularity in development and why it matters to evo-devo. American Zoologist. 40: $770-776$.

Brandley MC, Huelsenbeck JP, Wiens JJ. 2008. Rates and patterns in the evolution of snake-like body form in Squamate reptiles: evidence for repeated re-evolution of lost digits and long-term persistence of intermediate body forms. Evolution. 1-23.

Brock GT. 1929. On the development of the skull of Leptodeira hotamboia. Quarterly Journal of Microscopical Science. 73: 289-334.

Brock GT. 1932. Some developmental stages in the skulls of the geckos, Lygodactylus capensis and Pachydactylus maculosa, and their bearing on certain important problems in lacertilian craniology. South African Journal of Science. 29: 508-532.

Brock GT. 1935. The temporal bones in lizards, birds and mammals. Anatomisches Anzeiger. 80: $266-284$.

Brock GT. 1941. The skull of Acontias meleagris, with a study of the affinities between lizards and snakes. Journal of the Linnean Society (Zoology). 41: 71-88. 
Bryant SV, Gardiner DM. 1992. Retinoic acid, local cell-cell interactions and pattern formation in vertebrate limbs. Developmental Biology. 152:1-25

Burke AC, Nelson CE, Morgan BA, Tabin C. 1995. Hox genes and the evolution of vertebrate axial morphology. Development. 121: 333-346.

Buss LW. 1987. The evolution of individuality. Princeton University Press, Princeton. 103p.

Caldwell MW. 2003. "Without a leg to stand on": on the evolution and development of axial elongation and limblessness in tetrapods. Canadian Journal of Earth Science. 40: 573-588.

Camp CL. 1923. Classification of the Lizards. Bulletin on the American Museum of Natural History. $48: 289-481$.

Carroll RL. 1988. Vertebrate Paleontology and Evolution. WH Freeman and Company, New York.

Carroll RL. 1970. Quantitative aspects of the amphibian-reptilian transition. Forma et Functio. 3:165-178.

Carroll SB. 1995. Homeotic genes and the evolution of arthropods and chordates. Nature. 376: $479-485$.

Carroll SB. 200o. Endless forms: the evolution of gene regulation and morphological diversity. Cell. 101: 577-580.

Chan AOK, Dong M, Wang L, Chan WY. 2005. Somite as a morphological reference for staging and axial levels of developing structures in mouse embryos. Neuroembryology and Aging. 3(2): 102-110.

Charité J, de Graaff W, Vogels R, Meijlink F, Deschamps J. 1995. Regulation of the Hoxb-8 gene: synergism between multimerized cis-acting elements increases responsiveness to positional information. Developmental Biology. 171: 294-305.

Charité J, McFadden DG, Olson EN. 200o. The bHLH transcription factor dHAND controls Sonic hedgehog expression and establishment of the zone of polarizing activity during limb development. Development. 127: 2461-2470.

Chiang C, Litingtung Y, Harris MP, Simandl BK, Li Y, Beachy PA, Fallon JF. 2001. Manifestation of the limb prepattern: limb development in the absence of Sonic Hedgehog function. Developmental Biology. 236: 421-435.

Chimal-Monroy J, Rodriguez-Leon J, Montero JA, Ganan Y, Macias D, Merino R, Hurle JM. 2003. Analysis of the molecular cascade responsible for mesodermal limb chondrogenesis: Sox genes and BMP signaling. Developmental Biology. 257: 292-301. 
Christen B, Slack JMW. 1998. All limbs are not the same. Nature. 395: 230-231.

Claessens LPAM. 2004. Dinosaur gastralia; origin, morphology, and function. Journal of Vertebrate Paleontology 24: 89-106.

Cogger HG. 1992. Reptiles and amphibians of Australia. 5a edição. Ralph Curtis Books, Florida.

Cohn MJ, Tickle C. 1999. Developmental basis of limblessness and axial regionalization in snakes. Nature. 399: 474-479.

Cole CJ, Dessauer HC, Townsend CR e Arnold MG. 1990. Unisexual lizards of the genus Gymnophthalmus (Reptilia: Teiidae) in the neotropics: genetics, origin and systematics. American Museum Novitates. 2994: 1-29.

Cope ED. 1892. On degenerate types of scapular and pelvic arches in the lacertilia. Journal of Morphology. 7(2): 223-244.

Darwin C. 1859. On the origin of species. John Murray, London.

von Dassow G, Munro E. 1999. Modularity in animal development and evolution: elements of a conceptual framework for EvoDevo. Journal of Experimental Zoology (Mol Dev Evol). 285B: 307-325.

Dealy CN, Roth A, Ferrari D, Brown AM, Kosher RA. 1993. Wnt-5a and Wnt-7a are expressed in the developing chick limb bud in a manner suggesting roles in pattern formation along the proximodistal and dorsoventral axes. Mechanical Development. 43: 175-186.

Deeming DC, Ferguson MW. 1988. Environmental regulation of sex determination in reptiles. Philosophocal Transactions of the Royal Society of London. B. 322: 19-39.

Deeming DC, Ferguson MW. 1989. The mechanism of temperature-dependent sex determination in Alligator mississippiensis. Journal of Zoology. 200: 143-177.

Deeming DC, Ferguson MW. 1991. Physiological effects of incubation temperature on embryonic development in reptiles and birds. In: Egg incubation: its effects on embryonic development in birds and reptiles. Deeming DC, Ferguson MW, eds. P 147-172.

Dhouailly D, Saxod R. 1974. Les stades du développement de Lacerta muralis Laur. entre la ponte et l'eclosion. Bulletin Zoologique de France. 99: 489-494.

Dover G. 2000. How genomic and developmental dynamics affect evolutionary processes. BioEssays. 22: 1153-1159.

Dufaure JP, Hubert J. 1961. Table de développement du lézard vivipare: Lacerta (zootoca) vivipara Jacquin. Archives d'Anatomie microscopique et de Morphologie Expérimentale. 5O(3): 309-28. 
Echelard Y, Epstein DJ, St-Jacques B, Shen L, Mohler J, McMahon JA, McMahon AP. 1993. Sonic Hedgehog, a ember of a family of putative signaling molecules, is implicated in the regulation of CNS polarity. Cell. 75: 1417-1430.

El Mouden E, Bons J, Pieau C, Renous S, Znari M, Boumezzough A. 2ooo. Table de développement embryonnaire d'un lézard agamidé Agama impalearis Boettger, 1874. Annales des Sciences Naturelles. 21.3 (2000): 93-115.

El Toubi MR, Kamal AM. 1961a. The development of Ptyodactylus hasselquistii. I. The development of the chondrocranium. Journal of Morphology. 108: 63-94.

El Toubi MR, Kamal AM. 1961b. The development of Ptyodactylus hasselquistii. II. The fully formed chondrocranium. Journal of Morphology. 108: 165-192.

El Toubi MR, Kamal AM. 1961c. The development of Ptyodactylus hasselquistii. III. The osteocranium of a late embryo. Journal of Morphology. 108: 193-202.

Estes R, de Queiroz K, Gauthier J. 1988. Phylogenetic relationships within Squamata. In: Estes R, Pregill G, editors. Phylogenetic relationships of the lizard families. Stanford, Stanford University Press. p 199-281.

Etheridge R. 1965. The abdominal skeleton of lizards in the family Iguanidae. Herpetologica. 21: 161-168.

Etheridge R. 1967. Lizard caudal vertebrae. Copeia. 1967(4): 699-721.

Evans S. 2008. The skull of lizards and tuatara. In: Biology of the Reptilia. Vol 20, Morphology H. Gans C, Gaunt AS, Adler K, editors. Society for the Study of Amphibians and Reptiles. p 1-347.

Fan CH, Porter JA, Chiang C, Chiang DT, Beachy PA, Tessier-Lavigne M. 1995. Longrange sclerotome induction by Sonic Hedgehog: direct role of the amino-terminal cleavage product and modulation by the cyclic AMP signaling pathway. Cell. 81: 457-465.

Fang H, Elinson RP. 1996. Patterns of distal-less expression and inductive interactions in the head of the direct developing frog Eleutherodactylus coqui. Developmental Biology. 179: 160-172.

Fernandez-Teran H, Piedra ME, Kathiriya IS, Srivastava D, Rodriguez-Rey JC, Ros MA. 200o. Role of dHAND in the anterior-posterior polarization of the limb bud: implications for the Sonic hedgehog pathway. Development. 127: 2133-2142.

Fowler JÁ. 1970. Control of vertebral number in teleosts - an embryological problem. The Quarterly Review of Biology. 45(2): 148-167. 
Fromental-Ramain C, Warot X, Lakkaraju S, Favier B, Haack H, Birling C, Dierich A, Dollé P, Chambon P. 1996. Specific and redundant functions of the paralogous Hoxa-9 and Hoxd-9 genes in forelimb and axial skeleton patterning. Development. 122:461-472.

Gans C. 1975. Tetrapod limblessness: evolution and functional corollaries. American Zoologist. 15: $455-467$.

Gauthier JA, Estes R, de Queiroz K. 1988. A phylogenetic analusis of Lepidosauromorpha. In: Estes R, Pregill G, editors. Phylogenetic relationships of the lizard families. Stanford, Stanford University Press. p 15-98.

Gilbert SF. 2001. Ecological developmental biology: developmental biology meets the real world. Developmental Biology. 233: 1-12.

Gilbert SF. 2003. The morphogenesis of evolutionary developmental biology. International Journal of Developmental Biology. 47: 467-477.

Gilbert SF. 2006. Developmental Biology. 8th ed. Sinauer Associates. 814p.

Gilbert SF, Opitz JM, Raff RA. 1996. Resynthesizing evolutionary and developmental biology. Developmental Biology. 173: 357-372.

Gomez C, Özbudak EM, Wunderlich J, Baumann D, Lewis J, Pourquié O. 20o8. Control of segment number in vertebrate embryos. 454: 335-339.

Goodman CS, Coughlin BC. 2000. The evolution of evo-devo biology. Proceedings of the National Academy of Science, USA. 97(9): 4424-4425.

Goodrich, E.S., 1930. Studies on the Structure and Development of Vertebrates. Macmillan, London.

Gould SJ. 1977. Ontogeny and Phylogeny. Cambridge, MA. Harvard University Press.

Greenbaum E. 2002. A standardized series of embryonic stages for the emydid turtle Trachemys scripta. Canadian Journal of Zoology. 80: 1350-1370.

Greer AE. 1987. Limb reduction in the lizard genus Lerista. 1. Variation in the number of phalanges and presacral vertebrae. Journal of Herpetology. 21: 267-276.

Greer AE. 1990. Limb reduction in the scincid lizard genus Lerista. 2. Variation in the bone complements of the front and rear limbs and the number of postsacral vertebrae. Journal of Herpetology. 24: 142-150.

Greer AE. 1991. Limb reduction in squamates: identification of the lineages and discussion of the trends. Journal of Herpetology. 25: 166-173. 
Greer AE. 2002. The loss of the external ear opening in scincid lizards. Journal of Herpetology. 36: $544-555$.

Grieshammer U, Minowada G, Pisenti JM, Abbott UK, Martin GR. 1996. The chick limbless mutation causes abnormalities in limb bud dorsal-ventral patterning: implications for the mechanism of apical ridge formation. Development. 122: 3851-3861.

Guerra-Fuentes RA. 2006. O desenvolvimento embriológico do crânio do clado Iguania e sua contribuição para a filogenia do grupo (Reptilia, Squamata). Tese de Doutorado. Universidade de São Paulo, SP.

Guerra C, Montero R. 2009. The skull of Vanzosaura rubricauda (Squamata: Gymnophthalmidae). Acta Zoologica (Stockholm). 89: 1-13.

Hall BK. 1984. Developmental processes underlying heterochrony as an evolutionary mechanism. Cannadian Journal of Zoology. 62: 1-7.

Hall BK. 1992. Evolutionary Developmental Biology. Chapman \& Hall, Suffolk. 275p.

Hall BK. 200o. Evo-devo or devo-evo - does it matter? Evolution and Development. 2: 177-178.

Hall BK. 2003. Evo-Devo: evolutionary developmental mechanisms. International Journal of Developmental Biology. 47: 491-495.

Hall BK, Miyake T. 2ooo. All for one and one for all: condensations and the initiation of skeletal development. BioEssays. 22:138-147.

Hamburger V, Hamilton HL. 1951. A series of normal stages in the development of the chick embryo. Journal of Experimental Zoology. 88: 49-92.

Hammerschimidt M, Brook A, McMahon AP. 1997. The world according to hedgehog. Trends in Genetics. 13: 14-21.

Hanken J, Hall BK. 1993. The skull. Vol.1, Development. The University of Chicago Press, Chicago.

Hanken J, Wake DB. 1993. Miniaturization of body size: organismal consequences and evolutionary significance. Annual Review of Ecology and Systematic. 24:501-519.

Hanken J, Carl TF, Richardson MK, Olsson L, Schlosser G, Osabutey CK, Klymkowsky MW. 2001. Limb development in a "non-model" vertebrate, the direct-developing frog Eleutherodactylus coqui. Journal of Experimental Zoology (Mol Dev Evol). 291: 375-388.

Harfe BD, Scherz PJ, Nissim S, Tian H, McMahon AP, Tabin CJ. 2004. Evidence for an expansion-based temporal Shh gradient in specifying vertebrate digit identities. Cell. 118: 517-528. 
Herrel A, Aerts P. 2003. Biomechanical studies of food and diet selection. In: Nature Encyclopedia of Life Sciences. London: Nature Publishing Group.

Hirata M, Hall BK. 200o. Temporospatial patterns of apoptosis in chick embryos during the morphogenetic period of development. Journal of Developmental Biology. 44: 757-768.

Hopwood N. 2007. A history of normal plates, tables and stages in vertebrate embryology. International Journal of Developmental Biology. 51: 1-26.

Hoyos JM. 1998. A reappraisal of the phylogeny of lizards of the family Gymnophthalmidae (Sauria, Scincomorpha). Revista Espanola de Herpetologia 12: 27-43.

Hubert J. 1985. Embryology of the Squamata. In: Biology of the Reptilia. Gans C, Billet F, eds. Wiley \& Sons, New York. Vol.15, Development B. p 1-34.

Jackson K. 2002. Post-ovipositional development of the monocloed cobra, Naja kaouthia (Serpentes: Elapidae). Zoology. 105: 203-214.

Jerez A, Tarazona OA. 2009. Appendicular skeleton in Bachia bicolor (Squamata: Gymnophthalmidae): osteology, limb reduction and postnatal skeletal ontogeny. Acata Zoologica (Stockholm) 90: 42-50.

Jiang X, Iseki S, Maxson RE, Sucov HM, Morriss-Kay G. 2002. Tissue origins and interactions in the mammalian skull vault. Developmental Biology. 241: 106-116.

Johnson RL, Tabin CJ. 1997. Molecular models for vertebrate limb development. Cell. 90: 979-990.

Jones GM, Spell KE. 1963. A theoretical and comparative study of the functional dependence of the semicircular canal upon its physical dimensions. Proceedings of the Royal Society of London. B. 157: 403-419.

Kamal AM. 1965c. The mode of formation of the fenestrae basicranialis, $X$ and ovalis in Squamata. Zoologischer Anzeiger. 175: 285-288.

Kamal AM. 1965d. The origin of the interorbital septum of Lacertilia. Proceedings of the Egyptian Academy of Science. 18: 70-72.

Kamal AM. 1966a. The single origin of the parachordal plate in Squamata. Zoologischer Anzeiger. 176: 3-5.

Kamal AM. 1966b. The sphenoid bone in Lacertilia. Anatomisches Anzeiger. 118: 82-86.

Kamal AM. 1966c. On the hypoglossal foramina in Squamata. Anatomisches Anzeiger. 118: 91-96. 
Kamal AM. 1971. On the fissura metotica in Squamata. Bulletim of the Zoological Society of Egypt. 23: 53-57.

Kamal AM. 1972. The pterygoquadrate cartilage in Squamata. Zeitschrift fur Wissenschaftliche Zoologie. 185: 60-75.

Kamal AM, Zada SK. 1973. The early developmental stages of the chondrocranium of Agama pallida. Acta Morphologica Neerlando-Scandinavica. 11: 75-104.

Kardong KV. 1997. Vertebrates, comparative anatomy, function, evolution. Mc Graw-Hill, New York.

Kavanagh KD. 2003. Embedded molecular switches, anticancer selection, and effects on ontogenetic rates: a hypothesis of developmental constraint on morphogenesis and evolution. Evolution. 57(5): 939-948.

Kawakami Y, Rodríguez-León J, Koth CM, Buscher D, Itoh T, Raya A, Ng JK, Esteban CR, Takahashi S, Henrique D, Schwarz M, Asahara H, Belmonte JCI. 2003. MKP3 mediates the cellular response to FGF8 signalling in the vertebrate limb. Nature Cell Biology. 5(6): 513-519.

Kearney M. 2002. Appendicular skeleton in Amphisbaenians (Reptilia: Squamata). Copeia. 2002(3): 719-738.

Keynes RJ, Stern CD. 1988. Mechanisms of vertebrate segmentation. Development. 103: 413429.

Kimble J, Smith J. 1996. Pattern formation and developmental mechanisms. Current Opinion in Genetics \& Development. 6: 391-394.

Kohlsdorf T, Lynch VJ, Rodrigues MT, Brandley MC, Wagner GP. 2010. Data and data interpretation in the study of limb evolution: a reply to Galis et al. on the revolution of digits in the lizard genus Bachia. Evolution. 64(8): 2477-2485.

Kutschera U, Niklas KJ. 2004. The modern theory of biological evolution: an expanded synthesis. Naturwissenschaften. 91: 255-276.

Lande R. 1978. Evolutionary mechanisms of limb loss in tetrapods. Evolution. 32(1): 73-92.

Larson HCE, Wagner GP. 2002. Pentadactyl ground state of the avian wing. Journal of Experimental Zoology (Molecular Developmental Evolution). 294: 146-151.

Laufer E, Nelson CE, Johnson RL, Morgan BA, Tabin C. 1994. Sonic hedgehog and Fgf-4 ct through a signalin cascade and feedback loop to integrate growt and patterning of the developing limb bud. Cell. 79: 993-1003. 
Laufer E, Dahn R, Orozco OE, Yeo CY, Pisenti J, Henrique D, Abbot UK, Fallon JF, Tabin C. 1997. Expression of Radical fringe in limb-bud ectoderm regulates apical ectodermal ridge formation. Nature. 386: 366-373.

Lee MSY. 1998. Convergent evolution and character correlation in burrowing reptiles: towards a resolution of squamate relationships. Biological Journal of the Linnean Society. 65: 369-453.

Leitch AR, Schwarzacher T, Jackson D, Leitch IJ. 1994. In situ hybridization: a pratical guide. Royal Microscopy Handbooks, 27. Bios Scientific Publications, Oxford.

Lemus D, Duvauchelle R. 1966. Desarrollo intrauterino de Liolaemus tenuis tenuis (Dumeril y Bibron). Biologica. 39: 80-98.

Lewandoski M, Sun X, Martin GR. 2ooo. FGF8 signalling from the AER is essential for normal limb development. Nature genetics. 26: 460-463.

López AM, Cabrera MR. 1995. Osteología craneal de Pantodactylus schreibersii schreibersii (Wiegmann, 1834) y su contribución a la discusión de Gymnophthalmidae (Reptilia). Anales del Museo de Historia Natural de Valparaíso. 23: 53-62.

López-Martinez A, Chang DT, Chiang C, Porter JA, Ros MA, Simandl BK, Beachy PA, Fallon JF. 1995. Limb-patterning activity and restricted posterior localization of the aminoterminal product of Sonic hedgehog cleavage. Current Biology. 5: 791-796.

Love AC. 2003. Evolutionary morphology, innovation, and the synthesis of evolutionary and developmental biology. Biology and Philosophy. 18: 309-345.

Maisano JA. 200o. Postnatal skeletal development in Squamates: its relationship to life history and potential phylogenetic informativeness. Tese de doutorado. Yale University.

Maisano JA. 2001. A survey of state of ossification in neonatal squamates. Herpetological Monographs. 15: 135-157.

Maisano JA. 2002. The potential utility of postnatal skeletal developmental patterns in squamate phylogenetics. Zoological Journal of the Linnean Society. 136:277-313.

Marigo V, Tabin CJ. 1996. Regulation of Patched by Sonic Hedgehog in the developing neural tube. Proceedings of the National Academy of Science USA. 93: 9346-9351.

Martins JM. 1997. Estudo alozímico de um grupo de lagartos gimnoftalmídeos (Squamata: Gymnophthalmidae). Tese de Doutorado, Universidade de São Paulo, SP.

Maynard Smith J, Burian R, Kauffman S, Alberch P, Campbell J, Goodwin B, Lande R, Raup D, Wolpert L. 1985. Developmental constraints and evolution: a perspective from the mountain lake conference on development and evolution. The Quarterly Review of Biology. $60(3): 265-287$. 
Mayr E. 1993. What was the evolutionary synthesis? Trends in Ecology and Evolution. 8: 31-34.

MacLean WP. 1974. Feeding and locomotor mechanisms of teiid lizards: functional morphology and evolution. Papéis Avulsos de Zoologia, São Paulo. 27(15): 173-213.

Montero JA, Hurlé JM. 2007. Deconstructing digit chondrogenesis. BioEssays. 29: 725-737.

Montero R, Gans C. 1999. The head skeleton of Amphisbaena alba Linnaeus. Annals of the Carnegie Museum 68: 15-80.

Montero R, Moro SA, Abdala V. 2002. Cranial anatomy of Euspondylus acutirostris (Squamata: Gymnophthalmidae) and its placement in a modern phylogenetic hypothesis. Russian Journal of Herpetology 9: 215-228.

Mosauer W. 1932. On the locomotion of snakes. Science. $76: 583-585$.

Mullen LM, Bryant SV, Torok MA, Blumberg B, Gardiner DM. 1996. Nerve dependency of regeneration: the role of Distal-less and FGF signaling in amphibian limb regeneration. Development. 122: 3487-3497.

Muller GB. 1991. Evolutionary transformation of limb pattern: Heterochrony and secondary fusions. In: Developmental Patterning of the Vertebrate Limb. Hinchliffe JR, eds. Plenum Press, New York. p. 395-405.

Muller J. 2002. Skull osteology of Parvilacerta parva, a small-sized lacertid lizard from Asia Minor. Journal of Morphology. 253: 43-50.

Müller J. 2003. Early loss and multiple return of the lower temporal arcade in diapsid reptiles. Naturwissenschaften. 90:473-476.

Muth A. 1980. Physiological ecology of desert iguana (Dipsosaurus dorsalis) eggs: temperature and water relations. Ecology. 61: 1335-1343.

Muthukkaruppan et al., 1970. Analysis of the development of the lizard Calotes versicolor; Journal of Morphology. 130: 479-490.

Nelson CE, Morgan BA, Burke AC, Laufer E, DiMambro E, Murtaugh LC, Gonzales E, Tessarollo L, Parada LF, Tabin C. 1996. Analysis of Hox gene expression in the chick limb bud. Development. 122: 1449-1466.

Niswander L, Jeffrey S, Martin GR, Tickle C. 1994. A positive feedback loop coordinates growth and patterning in the vertebrate limb. Nature. 371: 609-612.

Ohuchi H, Nakagawa T, Yamamoto A, Araga A, Ohata T, Ishimaru Y, Yoshioka H, Kuwana T, Nohno T, Yamasaki M, Itoh N, Noji S. 1997. The mesenchymal factor, FGF10, initiates and maintains the outgrowth of the chick limb bud through interaction with 
FGF8, an apical ectodermal factor. Development. 124: 2235-2244.

Parr BA, Shea MJ, Vassileva G, McMahon AP. 1993. Mouse Wnt genes exhibit discrete domains of expression in the early embryonic CNS and limb buds. Development. 119: 247-261.

Pascoal S, Andrade RP, Bajanca F, Palmeirim I. 2007. Progressive mRNA decay establishes na MKP3 expression gradient in the chick limb bud. Biochemical and Biophysical Research Communications. 352: 153-157.

Pasteels JJ. 1970. Développement embryonnaire. In: Traitée de Zoologie. Anatomie, Systématique, Biologie. Grassé P, ed. Masson et Cie, Paris. Tome XIV, Reptiles. p 893-972.

Pellegrino KCM, Rodrigues MT e Yonenaga-Yassuda Y. 1999a. Chromosomal polymorphisms due to supernumerary chromosomes and pericentric inversions in the eye-lid less microteiid lizard Nothobachia ablephara (Squamata, Gymnophthalmidae). Chromosome Research. 7(4): 247-254.

Pellegrino KCM, Rodrigues MT e Yonenaga-Yassuda Y. 1999b. Chromosomal evolution in Brazilian lizards of genus Leposoma (Squamta, Gymnophthlamidae) from Amazon and Atlantic forests: banding patterns and FISH of telomeric sequences. Hereditas. 131: 15-21.

Pellegrino KCM, Rodrigues MT, Yonenaga-Yassuda Y, Sites JW. 2oo1. A molecular perspective on the evolution of microteiid lizards (Squamata, Gymnophthalmidae), and a new classification for the family. Biological Journal of the Linnean Society. 74: 315-38.

Pianka ER. 1986. Ecology and natural history of desert lizards : analyses of the ecological niche and community structure. Princeton, N.J.: Princeton University Press.

Poe S. 2004. A test for patterns of modularity in sequences of developmental events. Evolution. 58(8): $1852-1855$.

Potthoff T. 1983. Clearing and Staining Techniques. In: Ontogeny and Systematics of Fishes. American Society of Ichthyologists and Herpetologists.

Pough FH, Janis CM, Heiser JB. 2002. Vertebrate Life. 6a edição. Prentice Hall, New Jersey. 699p.

Pough FH, Andrews RM, Cadle JE, Crump ML, Savitzky AH, Well KD. 2004. Herpetology. 3a edição. Prentice-Hall, New Jersey.

Pourquié O. 2003. The segmentation clock: converting embryonic time into spatial pattern. Science. 301: 328-330.

Presch W. 1975. The Evolution of Limb Reduction in the Teiid Genus Bachia. Bulletin of the Southern California Academy of Sciences. 74: 113-121. 
Presch W. 1980. Evolutionary history of the South American microteiid lizards (Teiidae: Gymnophthalminae). Copeia 1980: 36-56.

Presch W. 1983. The lizard family Teiidae: is it a monophyletic group? Zoological Journal of the Linnean Society 77: 189-197.

Raff RA. 1996. The Shape of Life: Genes, Development and the Evolution of Animal Form. Chicago University Press, Chicago. 544p.

Raff RA. 2000. Evo-devo: the evolution of a new discipline. Nature Genetics. 1: 74-79.

Raff RA, Kaufman TC. 1983. Embryos, Genes and Evolution. Macmillan, New York, 395p.

Raff EC, Raff RA. 2ooo. Dissociability, modularity, evolvability. Evolution and Development. 2(5): $235-237$.

Raff RA, Sly BJ. 200o. Modularity and dissociation in the evolution of gene expression territories in development. Evolution and Development. 2(2): 102-113.

Raff RA, Wray GA. 1989. Heterochrony: developmental mechanisms and evolutionary results. Journal of Evolutionary Biology. 2:409-434.

Rahmani TH. 1974. Le développement et la regression des bourgeons des members antérieurs chez l'Ophisaure (Ophisaurus apodus Pallas). Annales d'Embryologie et de Morphogenèse. 7: 159-170.

Ramaswami LS. 1946. The chondrocranium of Calotes versicolor with a description of the osteocranium of a just-hatched young. Quarterly Journal of Microscopical Science. 87: 237-297.

Rasband WS. 1997-2010. ImageJ. US National Institutes of Health, Bethesda, Maryland, USA, http://rsb.info.nih.gov/ij// (obtido 04/o6)

Raynaud A. 1962. Les ébauches des members de l'embryon d'Orvet (Anguis fragilis L.). Comptes rendus des Scéances de l’Académie des Sciences, Paris, serie D. 254: 3449-3451.

Raynaud A. 1963. La formation et la regression des ébauches des members de l'embryon d'Orvet (Anguis fragilis L.) Observations effectuées sur les ébauches des members postérieurs. Bulletin de la Societé zoologique de France. 88: 299-324.

Raynaud A. 1972. Sur la dégénérescence cellulaire dans le constituent somitique de la partie mésoblastique de l'ébauche de member de l'embryon d'orvet (Anguis fragilis L.). C.r.Séanc. Acad. Sci., Paris. 274: 1835-1838.

Raynaud A. 1977. Somites and morphogenesis in reptile limbs. In: Ede DA, Hinchliffe JR, Balls M., editors. Vertebrate limb and somite morphogenesis. Cambridge. Cambridge University Press. p 373-385. 
Raynaud A. 1985. Development of limbs and embryonic limb reduction. In: Biology of the Reptilia. Gans C, Billet F, eds. Wiley \& Sons, New York. Vol.15, Development B. p 59-148.

Raynaud A. 1990. Developmental mechanisms involved in the embryonic reduction of limbs in reptiles. International Journal of Developmental Biology. 34: 233-243.

Raynaud A. 1994. Donnés préliminaires sur I'allongement du corps et la somitogenèse chez les jeunes embryons

d'Orvet (Anguis fragilis, L.) et de Lézard vert (Lacerta viridis, Laur.). Bull. Sot. Hist. Nat. Toulouse. 130: 47-52.

Raynaud A, Kan P. 1992. DNA synthesis decline involved in the developmental arrest of the limb buds in the embryos of the slow worm, Anguis fragilis (L.). International Journal of Developmental Biology. 36:303-310.

Raynaud A, Vasse J. 1968. Les relations entre les somites et les ébauches des members antérieurs chez l'embryon d'orvet (Anguis fragilis L.). Arch. Anat. micr. Morph. exp. 57: 227-254.

Raynaud A, Gasc J.P, Renous-Lecuru S. 1975. Les rudiments de membres et leur développement embryonnaire chez Scelotes inornatus (A. Smith), (Scincidae, Sauria). Bulletin Museum Natureal History Naturelle Paris. 3(298), Zool 208: 537-551.

Raynaud A, Gasc JP, Vasse J, Renous S, Pieau C. 1974. Relations entres les somites et les ébauches des members antérieurs, chez les jeunes embryons de Scelotes brevipes (Hewitt). Bullétin de la Societé zoologique de France. 99: 165-173.

Raynaud A, Kan P, Bouche G, Duprat AM. 1998. Effets de divers facteurs de croissance (FGF, IGF-1) sur les ébauches des membres de I'embryon d'orvet (Anguis fragilis L.). Annales des Sciences Naturelles. 3(4): 141-153.

Renous S, Hofling E e Gasc JP. 1995. Analysis of the locomotion pattern of two microteiid lizards with reduced limbs, Calyptommatus leiolepis and Nothobachia ablephara (Gymnophthalmidae). Zoology. 99(1995): 21-38.

Renous S, Hofling E e Gasc JP. 1999. On the rhythmical coupling of the axial and appendicular systems in small terrestrial lizards (Sauria: Gymnophthalmidae). Zoology. 102(1999): 31-49.

Rice EL. 1920. The development of the skull in the skink, Eumeces quinquelineatus L. Journal of Morphology. 34: 119-216.

Richardson MK. 1995. Heterochrony and the phylotypic period. Developmental Biology. 172: 412-421.

Richardson MK. 1999. Vertebrate evolution: the developmental origins of adult variation. BioEssays. 21: 604-613. 
Richardson MK e Keuck G. 2002. Haeckel's ABC of evolution and development. Biological Reviews. 77: 495-528.

Richardson MK, Carl TF, Hanken J, Elinson RP, Cope C, Bagley P. 1998. Limb development and evolution: a frog embryo with no apical ectodermal ridge (AER). Journal of Anatomy. 192: 379-390.

Richardson MK, Gobes SMH, van Leeuwen AC, Polman AE, Pieau C, Sanchez-Villagra M. 1999. Heterochrony in limb evolution: developmental mechanisms and natural selection. Journal of Experimental Zoology (Mol Dev Evol). 312B: 1-26.

Riddle RD, Johnson RL, Laufer E, Tabin C. 1993. Sonic hedgehog mediates the polarizing activity of the ZPA. Cell. 75: 1401-1416.

Riedl R. 1978. Order in Living Organisms: a Systems Analysis of Evolution. John Wiley \& Sons, New York. 313p.

Rieppel O. 1981. The skull and the jaw adductor musculature in some burrowing scincomorph lizards of the genera Acontias, Typhlosaurus and Feylinia. Journal of Zoology 195: 493-528.

Rieppel O. 1984a. Miniaturization of the lizard skull: its functional and evolutionary implications. Symposia of the Zoological Society of London. 52:503-520.

Rieppel O. 1984b. The cranial morphology of the fossorial lizard genus Dibamus with a consideration of its phylogenetic relationships. Journal of Zoology, London 204: 289-327.

Rieppel 0. 1985. The recessus scalae tympani and its bearing on the classification of reptiles. Journal of Herpetology. 19: 373-384.

Rieppel 0. 1987. The development of the trigeminal jaw adductor musculature and associated skull elements in the lizard Podarcis sicula. Journal of Zoology, London. 212: 131-150.

Rieppel O. 1992a. Studies on Skeleton Formation in Reptiles. III. Patterns of Ossification in the Skeleton of Lacerta vivipara Jacquin (Reptilia, Squamata). Fieldiana (Zoology). 68: 1-25.

Rieppel O. 1992b. Studies on skeleton formation in reptiles. I. The postembryonic development of the skeleton in Cyrtodactylus pubisulcus (Reptilia, Gekkonidae). Journal of Zoology (London). 227: 87-100.

Rieppel O. 1993a. Patterns of diversity in the reptilian skull. In: The Skull. vol 2. Patterns of Structural and Systematic Diversity. Hanken J, Hall BK, eds. The University of Chicago Press, Chicago. p 344-389.

Rieppel O. 1993b. Studies on skeleton formation in reptiles. II. Chamaeleo hoehnelii (Squamata: Chamaeleoninae), with comments on the homology of carpal and tarsal bones. Herpetologica. 49: 66-78. 
Rieppel O. 1993c. Studies on skeleton formation in reptiles. IV. The homology of the reptile (amniote) astragalus revisited. Journal of Vertebrate Paleontology. 13: 31-47.

Rieppel, O. 1994. Studies on Skeleton Formation in Reptiles. Patterns of Ossification in the Skeleton of Lacerta agilis exigua Eichwald (Reptilia, Squamata). Journal of Herpetology. 28: 145-153.

Rieppel O. 1996. Miniaturization in tetrapods: consequences for skull morphology. Symposia of the Zoological Society of London. 69: 47-61.

Rieppel O, Gronowski RW. 1981. The loss of the lower temporal arcade in diapsid reptiles. Zoological Journal of the Linnean Society. 72(3): 203-217.

Rieppel O, Zaher H. 20oo. The intramandibular joint in Squamates, and the phylogenetic relationships of the fossil snake Pachyrhachis problematicus Haas. Fieldiana-Geology. 43: 1-69.

Rieppel O, Zaher H. 2001. The development of the skull in Acrochordus granulatus (Schneider) (Reptilia: Serpentes), with special consideration of the otico-occipital complex. Journal of Morphology. 249: 252-266.

Robert JS. 2002. How developmental is evolutionary developmental biology? Biology and Philosophy. 17: 591-611.

Rocha PLB. 1998. Uso e partição de recursos por uma comunidade de lagartos das dunas interiores do Rio São Francisco (Squamata). Tese de Doutorado. Universidade de São Paulo, Brasil.

Rodrigues MT. 1984. Nothobachia ablephara: novo gênero e espécie do nordeste do Brasil (Sáuria, Teiidae). Papéis Avulsos de Zoologia. 35(28): 361-366.

Rodrigues MT. 1991a. Herpetofauna das dunas interiores do rio São Francisco, Bahia, Brasil. I. Introdução à área e descrição de um novo gênero de microteiideos (Calyptommatus) com notas sobre sua ecologia, distribuição e especiação (Sauria, Teiidae). Papéis Avulsos de Zoologia. 37(19): 285-320.

Rodrigues MT. 1991b. Herpetofauna das dunas interiores do rio São Francisco, Bahia, Brasil. II. Psilophthalmus: um novo gênero de microteiidae sem pálpebra (Sauria, Teiidae). Papéis Avulsos de Zoologia. 37(20): 321-327.

Rodrigues MT. 1991c. Herpetofauna das dunas interiores do rio São Francisco, Bahia, Brasil. III. Procellosaurinus: um novo gênero de microteiídeos sem pálpebra, com a redefinição do gênero Gymnophthalmus (Sauria, Teiidae). Papéis Avulsos de Zoologia. 37(21): 329-342.

Rodrigues MT. 1993a. Herpetofauna das dunas interiores do rio São Francisco: Bahia: Brasil. V. Duas novas espécies de Apostolepis (Serpentes, Colubridae). Memoriais do Instituto Butantan. 54(2): 53-59 (1992). 
Rodrigues MT. 1993b. Herpetofauna of palaeoquaternary sand dunes of the middle São Francisco river: Bahia: Brazil. VI. Two new species of Phimophis (Serpentes: Colubridae) with notes on the origin of psammophilic adaptations. Papéis Avulsos de Zoologia, São Paulo. 38(11): 187-198.

Rodrigues MT. 1995. Filogenia e história geográfica de uma radiação de lagartos microteídeos (Sauria, Teiioidea, Gymnophthalmidae). Unpublished Thesis. Universidade de São Paulo, Brazil.

Rodrigues MT. 1996. Lizards, snakes and amphisbaenians from the Quaternary sand dunes of the middle Rio São Francisco: Bahia: Brazil. Journal of Herpetology. 30(4): 513-523.

Rodrigues MT. 2002. Herpetofauna of the Quaternary sand dunes of the middle Rio São Francisco: Bahia: Brazil. VIII. Amphisbaena arda sp. nov., a fuliginosa-like checkered patterned Amphisbaena (Squamata, Amphisbaenidae). Phyllomedusa. 1(2): 51-56.

Rodrigues MT e Juncá FA. 2002. Herpetofauna of the Quaternary sand dunes of the middle Rio São Francisco: Bahia: Brazil. VII. Typhlops amoipira, sp.n., a possible relative of Typhlops yonenagae (Serpentes, Typhlopidae). Papéis Avulsos de Zoologia, São Paulo. 42 (13): 325-333.

Rodrigues MT e dos Santos EM. 2008. A new genus and species of eyelid-less and limb reduced gymnophthalmid lizard from northeastern Brazil (Squamata, Gymnophthalmidae). Zootaxa. 1873: 50-60.

Rodrigues MT, Freire MEX, Pellegrino KCM, Sites Jr JW. 2005. Phylogenetic relationships of a new genus and species of microteiid lizard from the Atlantic forest of north-eastern Brazil (Squamata, Gymnophthalmidae). Zoologial Journal of the Linnean Society. 144: 543557.

Rodrigues MT, Cassimiro J, Pavan D, Curcio FF, Verdade VK, Pellegrino KCM. 2009. A new genus of microteiid lizard from the Caparó Mountains, Southeastern Brazil, with a discussion of relationships among Gymnophthalmidae (Squamata). American Museum Novitates. 3673: 10pp.

Rodrigues MT, Pellegrino KCM, Dixo M, Verdade VK, Pavan D, Argolo AJS, Sites JW. 2007. A new genus of microteiid lizard from the atlantic forests of State of Bahia, Brazil, with a new generic name for Colobosaura mentalis, and a discussion of relationships among the Heterodactylini (Squamata, Gymnophthalmidae). American Museum Novitates. 3565: 27pp.

Romer AS. 1956. Osteology of the Reptiles. The University of Chicago Press.

Roscito JG, Rodrigues MT. 2010. Comparative cranial osteology of fossorial lizards from the tribe Gymnophthalmini (Squamata, Gymnophthalmidae). Journal of Morphology. 271: 13521365. 
Rowe DA. Fallon JF. 1982. The proximodistal determination of skeletal parts in the developing chick leg. Journal of Embryology and Experimental Morphology. 68: 1-7.

Russel AP, Bauer AM. 2008. The appendicular locomotor apparatus of Sphenodon and normal-limbed Squamates. In: Biology of the Reptilia. Vol 21, Morphology I. Gans C, Gaunt AS, Adler K, editors. Society for the Study of Amphibians and Reptiles. p 1-465.

Saint Girons H. 1985. Comparative data on lepisdosaurian reproduction and some time tables. In: Biology of the Reptilia. Gans C., Billet F. eds. Vol15. p 35-58.

Sanger TJ, Losos JB, Gibson-Brown. 2008. A developmental staging series for the lizard genus Anolis: a new system for the integration of evolution, development and ecology. Journal of Morphology. 269: 129-137.

Saunders JW. 1948. The proximo-distal sequence of origin of the parts of the chick wing and the role of ectoderm. The Journal of Experimental Zoology. 108: 363-403.

Saunders JW, Gasseling MT. 1968. Ectodermal-mesenchymal interactions in the origin of limb symmetry. In: Epithelial-Mesenchymal Interactions. Fleischmajer R e Billingham RE. The Williams \& Wilkins Company, Baltimore. pp. 78-97.

Schaerlaeken V, Herrel A, Aerts P, Ross CF. 2008. The functional significance of the lower temporal bar in Sphenodon punctatus. The Journal of Experimental Biology. 211: 3908-3914.

Sewertzoff AN. 1931. Studien über die Reduktion der Organe der Wirbeltiere. Zoologisches Jahrbuch (Abteilung für Anatomie). 53: 611-700.

Shapiro MD. 2002. Developmental morphology of limb reduction in Hemiergis (Squamata: Scincidae): chondrogenesis, osteogenesis, and heterochrony. Journal of Morphology. 254: 211-231.

Shapiro MD, Hanken J, Rosenthal N. 2003. Developmental basis of evolutionary digit loss in the Australian lizard Hemiergis. Journal of Experimental Zoology (Mol Dev Evol). 297B: $48-56$

Shine R, Wall M. 20o8. Interactions between locomotion, feeding, and bodily elongation during the evolution of snakes. Biological Journal of the Linnean Society. 95: 293-304.

Shubin NH, Alberch P. 1986. A morphogenetic approach to the origin and basic organization of the tetrapod limb. In: Evolutionary Biology. Hecht MK, Wallace B, Prance G, eds. Vol. 20. Plenum Press, New-York. Pp. 319-388.

Shubin NH, Marshal CR. 20oo. Fossils, genes and the origin of novelty. Paleobiology. 26(4): 324-340.

Slack JMW, Holland PWH, Grahm CF. 1993. The zootype and the phylotypic stage. Nature. 
361: $490-492$.

Soares M. 200o. Estudo do esqueleto cefálico de Anotosaura Amaral, 1933, Bachia Gray, 1845 e Heterodactylus Spix, 1825 (Squamata, Teiioidea, Gymnophthalmidae). Boletim do Museu Nacional, Rio de Janeiro. 426: 1-20.

Song J, Parenti LR. 1995. Clearing and staining whole fish specimens for simultaneous demonstration of bone, cartilage and nerves. Copeia. 1: 114-118.

Springer VG, Johnson GD. 20oo. Use and advantage of ethanol solution of alizarin red S dye for staining bone in fishes. Copeia. 2000(1): 300-301.

Stokely PS. 1947. Limblessness and correlated changes in the girdles of a comparative morphological series of lizards. American Midiland Naturalist. 38: 725-754.

Stopper GF, Wagner GP. 2005. Of chicken wings and frog legs: a smorgasbord of evolutionary variation in mechanisms of tetrapod limb development. Developmental Biology. 288: 2139 .

Stopper GF, Wagner GP. 2007. Inhibition of sonic hedgehog signaling leads to posterior digit loss in Ambystoma mexicanum: parallels to natural digit reduction in Urodeles. Developmental Dynamics. 236: 321-331.

Summerbell D. 1974. A quantitative analysis of the effect of excision of the AER from the chick limb-bud. Journal of Embryology and Experimental Morphology. 32: 651-660.

Sun X, Mariani FV, Martin GR. 2002. Functions of FGF signalling from the apical ectodermal ridge in limb development. Nature. 418: 501-508.

Tam PP. 1981. The control of somitogenesis in mouse embryos. Journal of Embryology and Experimental Morphology. 65 Supplement 103-128.

Tarazona OA, Fabrezi M, Ramirez-Pinilla MP. 20o8. Cranial morphology of Bachia bicolor (Squamata: Gymnophthalmidae) and its postnatal development. Zoological Journal of the Linnean Society. 152: 775-792.

Taylor WR, Van Dyke G. 1985. Revised procedures for staining and clearing small fishes and other vertebrates for bone and cartilage study. Cybium. 9(2): 107-119.

Thewissen JGM, Fish FE. 1997. Locomotor evolution in the earliest cetaceans; functional model, modern analogues, and paleontological evidence. Paleobiology. 23: 482-490.

Thewissen JGM, Cohn MJ, Stevens LS, Bajpal S, Heyning J, Horton Jr WE. 2006. Developmental basis for hind-limb loss in dolphins and origin of the cetacean bodyplan. Proceedings of the National Academy of Science, USA. 103 (22): 8414-8418. 
Thomson KS. 1988. Morphogenesis and Evolution. Oxford University Press, New York. 154p.

Tickle C. 2006. Making digit patterns in the vertebrate limb. Nature Reviews. 7: 45-53

Tickle PG, Ennos AR, Lennox LE, Perry SF, Codd JR. 2007. Functional significance of the uncinate processes in birds. The Journal of Experimental Biology. 210: 3955-3961.

Torres-Carvajal O. 2003. Cranial osteology of the Andean Lizard Stenocercus guentheri (Squamata: Tropiduridae) and its postembryonic development. Journal of Morphology. 255: 94-113.

Towers M e Tickle C. 2009. Growing models of vertebrate limb development. Development. 136: 179-190.

Uetz P. 2007. The reptile database: http://www.reptile-database.org.

van Bemmelen JF. 1889. Ueber die Herkunft der Extremitäten-und Zungen-muskulatur bei Eidechsen. Anat. Anz. 4: 240-255.

Vanzolini PE. 1991a. Two new small species of Amphisbaena from fossil dune field of the middle Rio São Francisco, State of Bahia, Brasil (Reptilia, Amphisbaenia). Papéis Avulsos de Zoologia, São Paulo. 37(17): 259-276.

Vanzolini PE. 1991b. Two further new species of Amphisbaena from the semi-arid northeast of Brasil (Reptilia, Amphisbaenia). Papéis Avulsos de Zooogia, São Paulo. 37(23): 247-361.

Vanzolini PE, Ramos-Costa AMM e Vitt LJ. 1980. Répteis das Caatingas. Academia Brasileira de Ciências, Rio de Janeiro.

Vasse J, Gasc JP, Renous-Lecuru S. 1974. Les membres rudlmentaires chez I'adulte et chez I'embryon de Scelores brevlpes (Hewitt) (Scincidae. Sauria). Ann. Embryol. Morphol. 7:417424 .

Verbout AJ. 1985. The development of the vertebral column. Adv. Anat. Embryol. Cell Biol. 90: 1-122.

Vitt, L. J. 1995. The ecology of tropical lizards in the caatinga of northeast Brazil. Occasional Papers of the Oklahoma Museum of Natural History. 1: 1-29.

Vogel A, Rodriguez C, Izpisúa-Belmonte JC. 1996. Involvement of FGF-8 in initiation, outgrowth and patterning of the vertebrate limb. Development. 122: 1737-1750.

Vonk FJ, Richardson MK. 20o8. Serpent clocks tick faster. Nature. 454: 282-283.

Wagner GP. 2001. What is the promise of developmental evolution? Part II: a causal explanation of evolutionary innovations may be impossible. Journal of Experimental Zoology (Mol 
Dev Evol). 291: 305-309.

Wagner GP e Laubichler MD. 2004. Rupert Riedl and the re-synthesis of evolutionary and developmental biology: body plans and evolvability. Journal of Experimental Zoology (Mol Dev Evol). 302B: 92-102.

Wiens JJ, Slingluff JL. 2001. How lizards turn into snakes: a phylogenetic analysis of bodyform evolution in anguid lizards. Evolution. 55: 2303-2318.

Wiens JJ, Brandley MC, Reeder TW. 2006. Why does a trait evolve multiple times within a clade? Repeated evolution of snake-like body form in squamate reptiles. Evolution. 60: $123-141$.

Wu X. 2003. Functional morphology of the temporal region in the Rhynchocephalia. Canadian Journal of Earth Sciences. 40: 589-607.

www.devbio.com - acesso de outubro de 2007 a agosto de 2010.

Yaron Z. 1985. Reptile placentation and gestation: structure, function, and endocrine control. In: Biology of the Reptilia. Gans C, Billet F. eds. Vol.15. p 528-603.

Yonenaga-Yassuda Y, Vanzolini PE, Rodrigues MT e Carvalho CM. 1995. Chromosome banding patterns in the unisexual microteiid Gymnophthalmus underwoodi in two related sibling species (Gymnophthalmidae, Sauria). Cytogenetic and Cell Genetics. 70: 29-34.

Yonenaga-Yassuda Y, Mori L, Chu TH e Rodrigues MT. 1996a. Chromosomal banding patterns in the eyelid-less microteiid radiation: Procellosaurinus and Vanzosaura (Squamata, Gymnophthalmidae). Cytogenetic and Cell Genetics. 74: 203-210.

Yonenaga-Yassuda Y e Rodrigues MT. 1999. Supernumerary chromosome variation, heteromorphic sex chromosomes and banding patterns in microteiid lizards of the genus Micrablepharus (Squamata, Gymnophthalmidae). Chromosome Research. 7: 21-29.

Zakany J, Duboule D. 2007. The role of Hox genes during vertebrate limb development. Current Opinion in Genetics \& Development. 17: 359-366.

Zehr DR. 1962. Stages in the normal development of the common garter snake, Thamnophis sirtalis sirtalis. Copeia. 1962(2): 322-329. 